\title{
NURSING CONSIDERATIONS TO COMPLEMENT THE SURVIVING SEPSIS CAMPAIGN GUIDELINES
}

\section{Authors:}

Leanne M Aitken, RN, PhD, FRCNA

Research Centre for Clinical and Community Practice Innovation, Griffith University, Nathan, Queensland, Australia

Intensive Care Unit, Princess Alexandra Hospital, Woolloongabba, Queensland, Australia

Ged Williams, RN, MHA

Gold Coast Health Services District, Gold Coast, Queensland, Australia

Clinical Professor, Research Centre for Clinical and Community Practice Innovation, Griffith University, Gold Coast, Queensland, Australia

Maurene Harvey, RN, MPH

Consultants in Critical Care, Inc, Glenbrook, NV, USA

Stijn Blot, RN, CCRN, MNSc, PhD

General Internal Medicine and Infectious Diseases, Ghent University Hospital, Ghent, Belgium

Faculty of Medicine and Health Sciences, University Ghent, Ghent, Belgium

Faculty of Healthcare, University College Ghent, Ghent, Belgium

Ruth Kleinpell, RN, PhD

Center for Clinical Research \& Scholarship, Rush University Medical Center, Chicago, IL, USA

Sonia Labeau, RN, MNSc

Faculty of Medicine and Health Sciences, University Ghent, Ghent, Belgium, 
Faculty of Healthcare, University College Ghent, Ghent, Belgium

Andrea Marshall, RN, PhD

Faculty of Nursing and Midwifery, University of Sydney, NSW, Australia

Gillian Ray-Barruel, RN, Grad Cert ICU Nursing, BA (Hons)

Nursing Practice Development Unit, Princess Alexandra Hospital, Woolloongabba,

Queensland, Australia

Patricia A. Moloney-Harmon, RN, MS, CCNS, FAAN

Children's Services, Sinai Hospital of Baltimore, Baltimore, MD, USA

Wayne Robson, RN, MSc

Patient Safety Programme Lead - Nottingham University Hospitals, UK

Alexander P Johnson, RN, MSN, ACNP-BC, CCNS, CCRN

Advocate BroMenn Medical Center, Normal, Illinois

Nguk Lan Pang, RN, MSc

KK Women's and Children's Hospital, Singapore

Tom Ahrens, RN, DNS, FAAN

Barnes-Jewish Hospital, St. Louis, MO, USA

\section{Corresponding author}

Dr Leanne Aitken

Professor of Critical Care Nursing

Griffith University \& Princess Alexandra Hospital

Postal Address:

Nursing Practice Development Unit, Princess Alexandra Hospital

Ipswich Road, Woolloongabba QLD 4102, Australia

phone: +61 731767256 
fax: +6173176 7356

email: 1.aitken@griffith.edu.au

\section{Financial support}

This project was conducted under the auspices of the World Federation of Critical Care

Nurses (WFCCN), and no sponsorship or funding was received for this project. 


\section{NURSING CONSIDERATIONS TO COMPLEMENT THE SURVIVING SEPSIS CAMPAIGN GUIDELINES}

\section{ABSTRACT}

Objective: To provide a series of recommendations, based on the best available evidence, to guide clinicians providing nursing care to patients with severe sepsis.

Design: Modified Delphi method involving international experts and key individuals in subgroup work and electronic-based discussion among entire group to achieve consensus. Methods: We used the Surviving Sepsis Campaign Guidelines (SSC) as a framework to inform the structure and content of these guidelines. We used the Grades of Recommendation, Assessment, Development and Evaluation (GRADE) system to rate the quality of evidence from high (A) to very low (D) and to determine the strength of recommendations, with grade1 indicating clear benefit in the septic population and grade 2 indicating less confidence in the benefits in the septic population. In areas without complete agreement between all authors a process of electronic discussion of all evidence was undertaken until consensus was reached. This process was conducted independently of any funding.

Results: Sixty-three recommendations relating to the nursing care of severe sepsis patients are made. Prevention recommendations relate to education, accountability, surveillance of nosocomial infections, hand hygiene and prevention of respiratory, central-line related, surgical site and urinary tract infections, while infection management recommendations related to both control of the infection source and transmission based precautions.

Recommendations related to initial resuscitation include improved recognition of the deteriorating patient, diagnosis of severe sepsis, seeking further assistance and initiating early resuscitation measures. Important elements of hemodynamic support relate to improving both tissue oxygenation and macrocirculation. Recommendations related to supportive nursing care incorporate aspects of nutrition, mouth and eye care and pressure ulcer prevention and 
management. Pediatric recommendations relate to the use of antibiotics, steroids, vasopressors and inotropes, fluid resuscitation, sedation and analgesia and the role of therapeutic end points.

Conclusion: Consensus was reached regarding many aspects of nursing care of the severe sepsis patient. Despite this, there is an urgent need for further evidence to better inform this area of critical care.

\section{Keywords}

Sepsis, severe sepsis, septic shock, nursing care, guidelines, Surviving Sepsis Campaign

\section{Acknowledgements}

We acknowledge and appreciate the input of R. Phillip Dellinger M.D. during the inception of this project, particularly as it related to his experience with the development of the Surviving Sepsis Campaign Guidelines for the Management of Severe Sepsis and Septic Shock. We thank Gordon Speed for his review of the document in relation to comprehensiveness, logical flow and use of terminology. 


\section{BACKGROUND}

Sepsis, including severe sepsis and septic shock, continues to be a major healthcare problem internationally. Although mortality related to severe sepsis and septic shock have reduced slightly in the past decade, it remains above $20 \%(1,2)$. As part of the response to optimize care for this group of patients evidence-based clinical practice guidelines have been published by the Surviving Sepsis Campaign (SSC) to facilitate clinicians to improve the outcomes of patients with sepsis and septic shock $(3,4)$.

Although the SSC Guidelines (4) provide a comprehensive review of the medical management of patients with sepsis and septic shock, they are frequently silent on the nursing care that is essential for optimal outcome of these patients. Expert nursing knowledge and skill is required for both the identification of the deteriorating patient as a result of newly developed sepsis and the ongoing implementation of competent care for the known severe sepsis patient. The World Federation of Critical Care Nurses (WFCCN), as the premier organization for critical care nurses worldwide, consequently formed an international group of interested experts in the area to provide guidance for nursing care of severe sepsis patients.

This care is provided by every registered nurse, as well as many of the advanced practice nurses (e.g. Nurse Practitioner, Clinical Nurse Specialist or Consultant) who practice in the acute hospital setting. Internationally, advanced practice nursing roles vary in scope, education and authorization. Although the scope and requirements for some of these roles are designated by legislation, for example, the scope of practice of the nurse practitioner, many of the roles are professional extensions of the registered nurse role. Given this variation in nursing roles from one region or country to another, we have not attempted to limit the recommendations contained within this document to care provided only by registered nurses, but have extended it to cover the practice of all nurses, regardless of their specific role. 
Most of these recommendations relate to the adult septic patient, with the majority of interventions not tested in the pediatric patient. Despite this, many of the recommendations are likely to be applicable to the pediatric setting. Throughout the document we have identified where specific information confirming or denying application to patients in specific age groups exists. Recommendations specific to the pediatric septic patient are contained within section IV late in the document.

While this document is designed to provide guidance for every nurse who cares for patients with severe sepsis, we have also provided recommendations regarding practice in areas of joint responsibility with other members of the healthcare team. For example, nurses frequently influence which central venous catheters or endotracheal tubes are purchased and used, as well as provide care related to the device following insertion. In addition, although most nurses do not order drugs, they do participate in protocol development and often advocate for the timely ordering and administration of medications important to patient outcomes in severe sepsis. Consequently, it is essential that nurses are familiar with the best available evidence.

Of note, this document is not designed to provide information regarding strategies for implementation to ensure practice is based on these recommendations. Rigorous and comprehensive implementation and evaluation strategies are essential, but constitute a separate body of knowledge and as such are not reviewed in this document. Clinicians are encouraged to become familiar with appropriate strategies prior to implementing the recommendations outlined throughout this document.

The aim of this review is therefore to provide a series of recommendations, based on the best available evidence, to guide clinicians providing nursing care to patients with severe sepsis. 


\section{METHODS}

Sepsis, including severe sepsis and septic shock, has been well defined in the literature and inform these guidelines (Table 1). These guidelines for nursing care are designed to augment, not to replicate or replace, the current SSC Guidelines (4) and have been developed using the following methodology:

- WFCCN formed a team to develop guidelines for the nursing care of patients with sepsis; the organization appointed a coordinator (LMA) and an organizational sponsor $(\mathrm{GW})$

- Known experts in the field of sepsis care were invited to contribute to the guidelines

- Authors worked in sub-groups of two or three; wherever possible these authors represented different geographical regions of the world

- The broad structure of the SSC guidelines (4) was used to inform the structure and content of these guidelines for nursing care

- An additional section relating to prevention of infection and subsequent sepsis was added in recognition of the pivotal role that nurses provide in this area

- Each sub-group of authors undertook searches to locate any published literature that informed the nursing care of patients with severe sepsis

- Authors searched the literature referred to in the SSC guidelines (4), with searches expanding based on the section topics

- Analogous to the SSC guidelines (4), the Grades of Recommendation, Assessment, Development and Evaluation (GRADE) system (5), was used to rate the quality of the evidence (Table 2)

- Initial discussion of relevance and quality of the evidence was undertaken electronically within the sub-groups 
- All recommendations were reviewed by the coordinator as well as an independent reviewer (GRB), queries were discussed electronically with the sub-group, then with the entire author team where necessary

- The evidence supporting each recommendation, as outlined in the rationale, and the associated level of recommendation, was then forwarded to all authors who confirmed, or not, their support for each recommendation based on the rationale and summary of evidence in line with the GRADE system (5)

- Every recommendation that did not receive $100 \%$ agreement for the grade of support was subject to email discussion and exploration of additional evidence until consensus by all members of the author team was achieved.

This project was conducted under the auspices of the WFCCN, and no sponsorship or funding was received for this project. All authors report no conflict of interest with respect to the clinical recommendations or consensus based evidence ratings. 


\section{INFECTION PREVENTION}

\section{A. Education}

1. We recommend interactive, multifaceted, longitudinal educational programs and educational outreach to enhance guideline implementation. Traditional education approaches, such as incorporated passive education and information dissemination through conferences, web sites and didactic lectures, are often not effective (grade 1A).

2. We recommend educational initiatives to reduce healthcare-associated infection rates (grade 1C).

Rationale. Education is generally considered as a first step to increase awareness of a problem and as crucial for processes of change. A systematic review found that interactive, multifaceted, longitudinal educational programs and educational outreach enhance guideline implementation (6). More specifically, a systematic review that investigated the effect of education on the reduction in infection rates concluded that the implementation of educational interventions may considerably reduce healthcare associated infections (7).

\section{B. Accountability}

1. We suggest the promotion of a culture of patient safety and individual accountability (grade 2D).

Rationale. Recent trends have seen a transition from accepting healthcare-associated infection as an inevitable outcome of admission to the Intensive Care Unit (ICU) (8) towards personal accountability and a goal of zero tolerance in relation to hospital-acquired infections $(9,10)$. A systematic review of 30 reports of nosocomial infection found that at least $20 \%$ could be preventable (11). A major impediment to achieving zero tolerance towards hospital- 
acquired infection has been a lack of accountability of all levels of hospital staff (9). This attitude is shifting, with recognition that hospital management, as well as every healthcare worker, is responsible and accountable for ensuring patient safety including infection prevention and control $(9,10)$. Educating and empowering nurses to ensure infection control guidelines are followed by all staff has the potential to positively impact on hospital-acquired infections $(12,13)$.

\section{Surveillance of nosocomial infections}

1. We recommend a continuous surveillance program for the detection of nosocomial infection (grade 1B).

Rationale. Local surveillance systems (eventually integrated in a national surveillance program) allow benchmarking of nosocomial infection data and are therefore essential to guide and evaluate interventions to reduce infection rates. Surveillance systems combined with appropriate feedback contribute to reduced nosocomial infection risk (14-19).

\section{Hand hygiene}

1. We recommend hand antisepsis, irrespective of the use of gloves, between caring for different patients or between different care activities for the same patient, immediately before and after each episode of direct patient contact, and after any activity or contact that potentially results in hands becoming contaminated (grade 1B).

2. We recommend hand antisepsis by means of an alcohol-based hand rub (grade 1A).

3. We recommend hand washing with soap and water when hands are visibly soiled (grade 1A). 
4. We recommend the use of gloves when contact with blood or other potentially infectious materials, secretions, mucous membranes and non-intact skin could occur (grade 1D).

Rationale. Adequate hand antisepsis has proven to result in reduced infection rates (20, 21). The use of alcohol-based hand rub is particularly effective; in contrast with hand washing, it kills susceptible bacteria more rapidly and to a greater extent, is less time consuming, and skin health is better preserved when moisturizers are added. Hand disinfection after glove removal is necessary because gloves may have imperceptible defects or may be torn during use, resulting in contamination of hands. Hand washing is necessary when hands are visibly dirty because alcohol-based hand rub is ineffective in the presence of organic material. However, after hand washing, the use of alcohol-based hand rub remains mandatory $(20,21)$.

As a rule of thumb, a first step towards adequate hand hygiene consists of avoiding direct contamination of hands. The use of non-sterile, well fitting gloves is recommended whenever the risk of contamination exists. Gloves must be changed between separate tasks on one patient (when going from a dirty/contaminated to a clean body site) and in between different patients $(20-22)$.

\section{E. Site-specific considerations}

Most healthcare associated infections in the ICU are related to the use of therapeutic devices. These include ventilator-associated pneumonia (VAP), catheter-related bloodstream infection (CR-BSI), surgical site infection (SSI), and urinary tract infection (UTI) (23, 24).

Recommendations for their prevention are outlined below. 


\section{E1. Prevention of respiratory infections}

The development of pneumonia in patients mechanically ventilated with an artificial airway may affect $10-48 \%$ of patients (25-27). VAP is associated with a higher mortality rate, and significantly longer ICU length of stay and hospital costs $(24,27)$. However, VAP is often preventable, and application of practices such as education strategies $(28,29)$ and ventilator bundles $(30,31)$ have contributed to a reduction in VAP incidence. Strategies to prevent VAP should be considered in all patients with severe sepsis (32).

1. We recommend head-of-bed elevation $30-45^{\circ}$ for all critically ill and mechanically ventilated patients (grade 1B). Special attention should be given to maneuvers in which it is difficult to achieve a $30^{\circ}$ head-of-bed elevation, such as during bed bath or changing sheets. In such circumstances we recommend backrest elevation of at least $10^{\circ}$ should be maintained.

Rationale. Aspiration of upper airway secretions is a common event even in normal healthy adults (33). Semi-recumbent position in mechanically ventilated patients has been associated with lower levels of aspiration into the lower airways (34-36) and lower VAP incidence than the supine position (37-39). In patients receiving enteral nutrition, head-of-bed elevation is especially effective in reducing the risk of VAP (37). However, the feasibility of maintaining head-of-bed elevation in daily practice has been questioned by some authors (40, 41). Van Nieuwenhoven et al (41) achieved average head-of-bed elevation of only $28^{\circ}$ despite a target of $45^{\circ}$, while Song et al (40) achieved head-of-bed elevation $>30^{\circ}$ in $43.4 \%$ of patients. 
2. We recommend the use of an endotracheal tube with subglottic secretion drainage in patients expected to require mechanical ventilation for more than 72 hours (grade 1A).

Rationale. Impaired gag reflex leads to pooling of secretions in the posterior part of the oropharynx (42), with microaspiration of subglottic secretions leading to VAP. Subglottic secretion drainage is accomplished through use of a specially designed endotracheal or tracheotomy tube with a separate dorsal lumen that opens directly above the endotracheal tube cuff. Subglottic secretions drainage appears to be effective in preventing VAP (relative risk [RR] $0.51,95 \%$ confidence interval [95\% CI] 0.37-0.71) in patients expected to be mechanically ventilated for more than 72 hours (43).

3. We suggest the use of a silver-coated endotracheal tube be considered (grade 2A).

Rationale. In multicenter randomized controlled trials, a silver-coated endotracheal tube was demonstrated to reduce bacterial airway colonization as well as VAP in patients intubated 24 hours or more $(44,45)$. More studies that confirm the current findings are required.

4. We suggest the use of an endotracheal tube with a polyurethane cuff (grade 2B).

Rationale. In a single center randomized controlled trial, an endotracheal tube with a polyurethane cuff was shown to significantly reduce early onset post-operative pneumonia in cardiosurgical patients (46). More studies that confirm this result are required.

5. We recommend endotracheal cuff pressure be maintained at least $20 \mathrm{~cm} \mathrm{H}_{2} \mathrm{O}$, but not more than $30 \mathrm{~cm} \mathrm{H}_{2} \mathrm{O}$ (grade $1 \mathrm{C}$ ). 
Rationale. Inadequate cuff pressure is a risk factor for microaspiration of oropharyngeal secretions and subsequent pneumonia. One observational study among intubated patients not receiving antibiotic therapy showed that a persistent intracuff pressure below $20 \mathrm{~cm} \mathrm{H}_{2} \mathrm{O}$ was an independent predictor of VAP (RR 4.2, 95\% CI 1.1-15.9) (47). Cuff pressure should be maintained at the lowest pressure above $20 \mathrm{~cm} \mathrm{H}_{2} \mathrm{O}$ that prevents cuff leak.

6. We suggest heat and moisture exchangers (HME) should be changed between patients, every 5-7 days, or as clinically indicated (grade 2C).

Rationale. Humidification of inspired air to prevent mucosal injury may be achieved by using a heated humidifier, a heated humidifier with a heated-wire circuit, or passively using a HME. There are insufficient data to demonstrate a benefit in VAP reduction for any humidification device (48). No benefit in infection rates or functionality of ventilator circuits has been demonstrated when HMEs are changed every day compared to 5-7 days $(49,50)$.

7. We recommend ventilator circuits should not be changed routinely, except between patients (grade 1B).

Rationale. There is no evidence that routine ventilator circuit changes can reduce the incidence of VAP $(25,51)$. New ventilator circuits should be used for each patient, and circuit changes performed only if the circuit becomes visibly soiled or damaged (32).

8. We recommend the aspiration of endotracheal secretions in response to clinical signs, i.e. visible or audible signs of respiratory secretions, respiratory deterioration or other changes 
in the patient's condition that may be due to respiratory secretions, in intubated patients (grade 1C).

Rationale. Critically ill patients mechanically ventilated via a tracheal tube frequently require removal of tracheobronchial and upper airway secretions due to increased mucus production and a decreased ability to clear secretions $(52,53)$. Secretion removal may reduce infectious, respiratory and tube patency complications (54-56).

Suctioning should only be performed when necessary, using the lowest possible suction pressure, take no longer than 15 seconds, use continuous rather than intermittent suctioning; the suction catheter should occlude less than half the lumen of the endotracheal tube and be inserted no further than the carina; hyperoxygenation should be provided before and after suctioning, and saline lavage should be avoided $(55,57)$.

The optimum frequency of endotracheal suctioning has not been clearly determined, but should be in response to clinical signs (56). There is insufficient evidence to recommend the benefits of either an open or closed suctioning system (57).

9. We recommend regular mouth care and oral cavity assessment be provided to all critically ill and intubated patients (grade 1C).

Rationale. Colonization of the oropharynx by pathogens is a potential risk factor for the development of VAP (58-60). Critical illness contributes to changes in the oral flora, and an increase in gram-negative flora that includes more virulent organisms may occur $(61,62)$. Providing regular oral care, incorporating oral cavity assessment, is an important part of providing comfort to the critically ill patient (63) and is also demonstrated to contribute to a decrease in VAP (63-67). Assessment should include the condition of the teeth, gums, tongue, 
mucus membranes and lips, and barriers to mouth care delivery (63). The use of a designated oral care protocol, in association with an education program for nurses in its importance in preventing VAP, can increase compliance and assessment of mouth care (68).

10. We recommend the use of chlorhexidine-based antiseptic for oral care in intubated patients (grade 1A).

Rationale. Chlorhexidine is widely used and investigated in the oral care of intubated patients (69-72). Chlorhexidine effectively decontaminates the oropharynx $(73,74)$, and its use in oral care has been proven to decrease dental plaque (75) and incidence of respiratory infections (76), and substantially decrease the incidence of VAP (77-79). The optimal concentration of chlorhexidine solution $(0.12 \%, 0.2 \%$ or $2 \%)$ remains undetermined. The optimum frequency for oral care with chlorhexidine has not been demonstrated. In general, a frequency of 3-4 times daily is proposed $(69,80,81)$. The benefit of tooth brushing in critically ill patients as a component of oral care protocols has demonstrated efficacy but additional research is indicated $(65,66)$. Tap water is not recommended for oral care in the critically ill (63).

\section{E2. Prevention of central line-related bloodstream infections (CR-BSI)}

1. We recommend the implementation of a central line care bundle including staff education, creation of a catheter insertion cart, implementation of a checklist to ensure adherence to evidence based guidelines, empowering nurses to stop catheter insertion procedures when a guideline violation is observed, and daily assessment of possible catheter removal (grade 1B). 
Rationale. A bundle approach to central venous catheter (CVC) insertion and care (12, 13, 82,83 ) has proven to be effective in substantially reducing the rate of CR-BSI. Nurses play a key role in preventing CR-BSI through the activities outlined above.

2. We recommend the use of maximal sterile barriers during CVC insertion (grade 1A).

Rationale. During the CVC insertion procedure, all healthcare personnel involved must wear a mask, cap, sterile gown, and sterile gloves and the patient is to be covered with a large sterile drape (84-88). Use of maximal sterile barrier precautions during CVC insertion have led to reduced infection rates $(87,89,90)$.

3. We recommend the use of a chlorhexidine-based antiseptic for skin preparation before insertion and subsequent catheter care (grade 1A).

Rationale. As the risk of CR-BSI increases with the density of microorganisms at and around the insertion site (21), site antisepsis is crucial in the prevention of infection. Aqueous chlorhexidine (2\%) solution has consistently been found to be superior to both $10 \%$ povidone iodine and 70\% alcohol for preventing CR-BSI (91-93).

4. We suggest the replacement of administration sets every 96 hours (grade 2A), except when used for the administration of blood, blood products or lipids, in which case sets must be changed within 24 hours (grade 1A).

Rationale. A Cochrane systematic review found no increase in the risk for CR-BSI when the interval for administration set replacement was increased from 72 hours to 96 hours (94). 
When a fluid that enhances microbial growth is infused (lipid emulsions, blood products) more frequent changes of administration sets are indicated because these products have been identified as independent risk factors for CR-BSI in both adults and neonates (95-100).

5. We recommend the use of minocyclin-rifampin impregnated catheters (grade 1B).

Rationale. Studies have repeatedly demonstrated a significant reduction in CR-BSI with the use of impregnated CVCs in comparison with standard catheters (101-104); this reduction in infection rates has been greatest with minocycline-rifampin coated CVCs when compared to other impregnated CVCs (105). Minocycline-rifampin impregnated CVCs are approved for use in the pediatric population by the Food and Drug Administration (USA); however, studies have not been conducted in children.

\section{E3. Prevention of surgical site infections (SSI)}

1. We recommend that antimicrobial prophylaxis be administered within one hour before incision to maximize tissue concentration. Two hours are allowed for the administration of vancomycin and fluoroquinolones (grade 1A).

Rationale. In 2003, the Surgical Infection Prevention Guideline Writers Workgroup meeting reviewed the various guidelines for antimicrobial prophylaxis in surgery (106). On the basis of published evidence, the workgroup concluded that infusion of the first antimicrobial dose should begin within 60 minutes before incision, and when a fluoroquinolone or vancomycin is indicated the infusion should begin within 120 minutes before incision to prevent antibiotic-associated reactions $(106,107)$. 
2. We recommend that only hair that will interfere with the operation be removed, and that, if hair removal is necessary, it should be removed by using electric clippers (grade 1B).

Rationale. Although several authors have reported pre-operative hair removal is associated with increased SSI rates (108-111), a Cochrane systematic review compared a variety of hair removal methods (depilatory cream, razors, clippers) versus no hair removal and reported no difference in SSI rates among patients who had hair removal prior to surgery and those who did not (112). The same review found that shaving led to statistically significantly more SSIs compared with clipping or depilatory cream (112). The increased infection risk associated with the technique of shaving is attributed to the formation of microscopic cuts in the skin that later act as foci for bacteria (108). Although the use of depilatories has been associated with a lower SSI risk than shaving or clipping $(113,114)$ they can produce hypersensitivity reactions (114).

3. We recommend that blood glucose levels be controlled during the immediate postoperative period for patients undergoing cardiac surgery: controlled blood glucose level (lower than $200 \mathrm{mg} / \mathrm{dL}$ ) on post-operative day 1 and post-operative day 2, with procedure day being post-operative day 0 (grade $1 \mathrm{C}$ ).

Rationale. Increased glucose levels (>200 mg/dL) in the immediate post-operative period ( $\leq 48$ hours) are associated with increased SSI risk $(115,116)$. One study found that patients with a blood glucose level more than $300 \mathrm{mg} / \mathrm{dL}$ within 48 hours of surgery had more than three times the likelihood of a wound infection (117). Regular monitoring of glucose levels and timely administration of insulin and hyperglycemic agents is a direct nursing 
responsibility, therefore nursing education should stress the importance of glucose control in preventing SSI.

4. We recommend the identification and treatment of infections remote to the surgical site before elective surgery (grade 1B).

Rationale. Concurrent remote site infections are considered to increase SSI risk (118120). Therefore, whenever possible, all infections remote to the surgical site should be identified and treated before elective operation, and elective operations on patients with remote site infections should be postponed until the infection has resolved (108).

\section{E4. Prevention of urinary tract infections (UTI)}

1. We recommend that all attempts should be made to limit the duration of urinary catheterization (grade 1C).

Rationale. The urinary tract is the most prevalent source of nosocomial infection and there are several recommendations to prevent or reduce the incidence of UTI (121). Duration of catheterization is the most important risk factor for developing UTI (121). Post-operative urinary catheterization $>2$ days is associated with an increased likelihood of UTI and 30-day mortality, as well as a decreased likelihood of discharge to home (122). Nurses should advocate for prompt removal of urinary catheters (123) and discourage long-term catheterization, if possible.

2. We recommend that a sterile, continuously closed drainage system be maintained (grade 1A). 
Rationale. Closed urinary drainage systems are pivotal in preventing UTI $(21,123)$. The risk of infection reduces from $97 \%$ using open systems to $8-15 \%$ when sterile closed systems are used (124-126). Errors in maintaining sterile closed drainage and opening the closed drainage system have been well documented to predispose patients to infection $(124,126-$ 129).

3. We recommend regular perineal hygiene measures (grade $1 \mathrm{C}$ ).

Rationale. Most episodes of UTI are caused by the patient's own flora (121). Daily cleansing of the urethral meatus using soap and water or perineal cleanser is recommended $(123,130)$.

4. We suggest the maintenance of unobstructed urine flow (grade 2C).

Rationale. Reflux of urine is associated with infection; therefore, drainage bags should be positioned below the level of the bladder at all times to prevent urine back-flow and unobstructed urine flow should be maintained $(21,131,132)$.

\section{INFECTION MANAGEMENT}

\section{A. Infection source control issues}

1. We recommend prompt removal of intravascular catheters and subsequent catheter tip culturing in patients with proven bloodstream infection associated with severe sepsis as well as in hemodynamically unstable patients with suspected CR-BSI (grade 1C). 
Rationale. Prompt removal of contaminated invasive devices is a cornerstone in the management of device-related infection. Failure to remove the catheter was demonstrated to be an independent predictor of mortality in an epidemiological study on CR-BSI (OR 0.22, 95\% CI 0.10-0.86) (133). If the catheter is removed for suspected CR-BSI, guidewire exchange is acceptable in circumstances where catheter insertion is problematic as this reduces the risk for mechanical complications (134). If, however, the catheter tip culture appears to be positive, the newly inserted catheter should be replaced a second time because bacterial contamination can be expected and guidewire exchange on itself was shown to be an independent risk factor for the development of CR-BSI in an observational study (OR 4.59, 95\% CI 2.28-9.3) (133).

\section{B. Transmission-based precautions}

1. We recommend transmission-based precautions for patients who are known or suspected to be infected or colonized with infectious agents including certain epidemiologically important pathogens (grade 1A).

Rationale. Standard precautions are required for all patients. In addition, patients colonized or infected with epidemiologically important pathogens, including methicillinresistant Staphylococcus aureus; vancomycin-resistant enterococci, glycopeptide-resistant Staphylococcus aureus, extended-spectrum beta-lactamase producing Enterobacteriaceae, multidrug-resistant non-fermenting Gram-negative bacteria, and Clostridium difficile, may pose a potential threat to patients in their vicinity (135), and require additional precautions to prevent cross-infection. There are three categories of transmission-based precautions: contact, droplet and airborne precautions (136). For diseases with multiple routes of transmission, more than one transmission-based precautions category may be recommended. Transmission- 
based precaution categories and the particular measures they include are described in detail elsewhere (136).

\section{INITIAL RESUSCITATION}

As the SSC Guidelines (4) for initial resuscitation (six-hour resuscitation bundle) are operational only from the point that severe sepsis/septic shock is diagnosed, the processes that lead to early diagnosis are pivotal. Many of the processes that support compliance with the six-hour resuscitation bundle such as recording and interpreting clinical observations, seeking further assistance, and initiating early resuscitation measures are often the domain of nurses. The role of the nurse in initial resuscitation will vary according to the clinical area concerned. On a general ward nurses will be responsible for monitoring clinical observations, and giving antibiotics and fluid challenges, whereas in a critical care area nurses may be also be involved in monitoring hemodynamic status and administering vasoactive agents. The nurse's role in initial resuscitation does not end when medical staff arrive on the scene. Successful resuscitation depends on collaborative integration of the skills and expertise of all members of the multidisciplinary team.

\section{A. Recognizing deterioration and diagnosing severe sepsis}

1. We recommend that all staff with a direct responsibility for patient care (including nursing assistants and health care assistants) be educated to recognize the Systemic Inflammatory Response Syndrome (SIRS) criteria and signs of severe sepsis or septic shock (grade 1C).

Rationale. All staff with a direct responsibility for patient care, including the taking of vital signs, must be able to recognize the clinical findings of SIRS and sepsis (Table 3). The definitive diagnosis of sepsis or severe sepsis in hospital patients will often be made by a 
medical officer, but the clinical review leading to diagnosis will usually be facilitated by a nurse who recognizes signs and symptoms indicative of the onset of SIRS and/or sepsis (137).

Nurses therefore play a pivotal role in the early identification of deteriorating patients and prompt management of sepsis to enhance recovery (138). Numerous studies have demonstrated the relationship between nursing and failure-to-rescue $(139,140)$. The effect on patient outcomes of providing sepsis education for all nurses including nursing assistants is inconclusive. A national sepsis education program in Spain for medical and nursing staff marginally improved guideline compliance and hospital mortality rates $(44.0 \%$ vs. $39.7 \%$; $=$ .04) but did not demonstrate sustained improvement after one year (141). However a more recent multi-national performance improvement study demonstrated sustained improvement in both compliance and patient mortality at two years (142).

2. We recommend the use of early warning systems (EWS) to assist in the early recognition of sepsis in order to promote prompt treatment to enable best patient outcomes (grade 1C).

3. We suggest the use of sepsis screening tools to assist in the early recognition of sepsis in order to promote prompt treatment to enable best patient outcomes (grade 2C).

Rationale. Early diagnosis of sepsis is linked to improved outcomes and survival from sepsis. The recognition of patient deterioration and diagnosis of sepsis relies on the detection of abnormalities in physiological data. The collection and documentation of clinical observations is an important nursing role $(143,144)$. Despite this, there is evidence that clinical observations sometimes are performed poorly or not at all, are not documented, are not interpreted correctly, or are not reported when abnormalities are found (145). Early warning systems (EWS), also known as 'Track and Trigger' systems, have been promoted to aid in the detection of deterioration by highlighting abnormalities in clinical observations 
(146), however, the evidence of their effectiveness is inconclusive (147, 148). Additional verification of the usefulness of EWS is needed in order to recommend consistent use in clinical care.

The addition of sepsis screening tools have been recommended in promoting early recognition of patients at risk for developing or those who have SIRS criteria, indicating the early onset of severe sepsis $(146,149)$. Sepsis screening can be added to observation charts or EWS charts, prompting nurses to use a sepsis screening tool if the patient triggers one or more of the SIRS criteria of temperature, heart rate and respiratory rate (149). One study reported a decrease in mortality of one-third following the introduction of a three-step sepsis screening tool (150).

\section{B. Seeking further assistance}

1. We suggest that communication tools (e.g. SBAR, RSVP) be used to improve communication and promote prompt identification and treatment of patients with suspected or confirmed sepsis (grade 2D).

Rationale. Summoning medical assistance is crucial in implementing the resuscitation bundle, and communication delays can result in poorer outcomes for patients with severe sepsis. There is evidence that nurses and medical staff do not always communicate effectively with each other $(145,151)$. Communication between disciplines can be improved by using structured communication tools such as SBAR (Situation, Background, Assessment, Recommendations) (152, 153), RSVP (Reason, Story, Vital signs, Plan) (154) and EWS (155) that incorporate objective, unambiguous language to convey patient information. Sepsis screening tools may also be incorporated into the Assessment (SBAR) or Vital Signs (RSVP) 
to ensure the nurse cogently relays the message that the patient meets the consensus definition for severe sepsis and needs immediate attention to implement the resuscitation bundle.

\section{Initiating early resuscitation measures}

1. We suggest that the initial resuscitation of patients with sepsis be provided through the use of rapid response systems (grade $2 \mathrm{~B}$ ).

Rationale. Early recognition of sepsis can improve patient outcomes if a rapid response is initiated $(156,157)$. Early goal-directed therapy (EGDT) and the SSC guidelines have demonstrated efficacy in improving mortality outcomes in severe sepsis $(4,158,159)$. Despite this, compliance with the six-hour resuscitation bundle is poor, ranging from 19-52\% (160, 161). A number of studies have explored the poor uptake of EGDT and suggest barriers to implementation include inadequate facilities (162) and inadequate numbers of nurses (163).

Nurses must be able to recognize signs of severe sepsis and be knowledgeable about the six-hour bundle components in order to begin prompt implementation of therapy. The focus then should be on identifying patients eligible for EGDT (those not responding to fluid resuscitation and/or having a lactate $>4 \mathrm{mmol} / \mathrm{L}$ ) and arranging prompt transfer to a higher level of care area such as the High Dependency Unit and Intensive Care Unit to ensure timely treatment for severe sepsis. Table 5 outlines additional strategies for integrating the SSC guidelines in nursing practice (138).

2. We suggest the provision of adequate resources to enable prompt identification of patients with actual or suspected sepsis (grade 2D). 
Rationale. A recent UK survey of acute medical units found that only $12 \%$ appeared to have the minimum facilities to comply with the six-hour resuscitation bundle (162). Carrying out EGDT can be labor intensive and may require a minimum of two nurses in the initial phase (164), although some clinical settings can incorporate EGDT into their regular clinical duties without the allocation of additional staff (165). Recommended resources include arterial blood gas monitors, and laboratory facilities for measuring lactate levels as serum lactate has been demonstrated to be an independent predictor of mortality in patients with severe sepsis (166). Hand-held lactate monitors should be available in non-critical care areas to help identify those with cryptic shock (raised lactate in the absence of hypotension) who may otherwise be overlooked.

3. We recommend that adequate nurse staffing levels be ensured to provide quality patient care and improved patient outcomes (grade 1B).

Rationale. The impact of registered nurse staffing levels on patient outcomes is well documented, with lower nurse-patient ratios being associated with higher rates of pneumonia (167-171), shock, UTI (169), upper gastrointestinal bleeding, deep vein thrombosis, cardiac arrest and failure-to-rescue, as well as infection (172) and sepsis (167, 168, 170, 173-176). Nurse-to-patient ratios in ICUs in the USA and some parts of Europe typically range from 1:1 to 1:3 depending on patient acuity levels, while in countries such as Australia, New Zealand, and the UK, ratios are 1:1 due to not having personnel such as respiratory therapists to assist in the management of acute and critically ill patients. Nurse-to-patient ratios of one nurse caring for one or two patients $(>1: 2)$ versus one nurse caring for three or more patients $(<1: 2)$ in the ICU have been found to be associated with increased risk of post-operative pulmonary and infectious complications (167). 
4. We suggest that nurses be empowered to initiate the six-hour resuscitation bundle. All nurses should be trained to take blood, cannulate, and administer intravenous fluids via standing orders for hypotension and/or raised lactate (grade 2C).

5. We suggest that the 'Sepsis Six' approach be promoted in non-critical care areas in order to promote early identification and treatment of severe sepsis (144) (grade 2D).

Rationale. Although the nurse may identify signs of severe sepsis, he/she may be unable to initiate the resuscitation bundle interventions such as giving antibiotics and fluid boluses without a specific physician order. Standing order sets and established protocols have been utilized to facilitate early implementation of the bundle components (177).

In the United Kingdom poor uptake of EGDT in emergency departments (178) led to a change in focus of education to concentrate on care that could be delivered by staff without specialist skills and equipment in the first hour following diagnosis. This has been called the 'Sepsis Six' and includes six crucial interventions in sepsis resuscitation including starting high-flow oxygen, obtaining blood cultures, administering antibiotic therapy, starting intravenous fluid resuscitation, obtaining lab work including hemoglobin and lactate levels, and measuring hourly intake and output $(144,159,179)$ (Table 4). Nurses play an important role in each of these interventions. High-flow oxygen therapy is not currently included in the SSC guidelines (4), but is universally recommended as being an important aspect of resuscitation of the critically ill and should be initiated by nurses $(180,181)$. Many nurses perform venipuncture and can rapidly obtain blood for cultures and venous lactate assessment, or can ensure equipment is available promptly if they are unable to perform venipuncture. 
As a medical officer may not be always readily available, some hospitals have introduced measures to empower nurses to administer fluid challenges for hypotensive patients via standing orders or patient group directions to reduce delays in patients receiving fluid resuscitation (182). Protocol-directed care in the areas of fluid and vasopressor therapy is becoming more commonplace and has been shown to be safe $(177,183)$. In the UK and the USA, advanced practice nurses independently prescribe medications and can initiate orders for sepsis management, thus helping to facilitate early resuscitation measures $(184,185)$. Including nurses who are able to prescribe antibiotics, fluids and vasopressors on critical care outreach teams and rapid response system teams may also reduce delays in implementing the six-hour bundle.

EGDT incorporates blood transfusion for some patients and is recognized as a serious threat to patient safety; nurses play an important role in ensuring that patients who require transfusion receive blood in a safe manner guided by best evidence recommendations (186, 187).

6. We recommend that supplies of commonly used, ready-mixed antibiotics be available in all acute wards and departments (grade 1D).

Rationale. Usually it is nurses who administer antibiotics after a medical officer has prescribed them. Unfortunately antibiotic administration can be delayed up to six hours in some patients with bloodstream infection $(188,189)$. Reasons for such delays include lack of intravenous access and the prescribed antibiotic not being available (188). Measures such as having commonly used antibiotics and ready-mixed antibiotics available, as well as training nurses to cannulate should be considered (190). 
7. We suggest the institution of tracking systems including the use of daily sepsis rounds in critical care areas (grade 2C).

Rationale. Use of check sheets to monitor patients for signs of sepsis, or automated computer-based sepsis alert programs (191), can enhance identification of patients with sepsis.

8. We suggest ER nurses should liaise with medical colleagues and pre hospital staff to facilitate diagnosis and initial treatment of severe sepsis en route to hospital, and to promote 'alerting' of ERs that a patient with severe sepsis is expected (grade 2D).

Rationale. This system is already common practice for patients with acute coronary syndrome and major trauma, and may help to identify those patients eligible for EGDT (192).

9. We suggest further research on technology to aid the detection of sepsis (grade 2D).

Rationale. Technology that alerts nurses performing clinical observations and calculation of EWS such as Sepsis alert, Biosign, Vitalpac, etc. is currently being developed by many different biotechnology companies. Evidence of the benefit of this trend is yet to be confirmed.

\section{HEMODYNAMIC SUPPORT}

Hemodynamic monitoring techniques continue to develop and hemodynamic therapies for severe sepsis are essentially supportive care, aimed at improving both macro and microcirculation. The current SSC guidelines (4) are primarily based on an evidence-based 
practice guideline published in 2004 (193). Despite these excellent practice guidelines, questions remain in terms of the nursing care of septic patients with hemodynamic disturbances.

Complicating the care of patients with severe sepsis is the multimodal nature of the hemodynamics of sepsis. For example, in the early phase of sepsis, patients present with a relative hypovolemia that may be somewhat managed by restoring blood volume, i.e. restoring macrocirculation. However, as sepsis progresses, a disturbance that centers on the microcirculation is usually detected. At this point, the macrocirculation becomes hyperdynamic. Further treatment of the macrocirculation does little to address the problem of the microcirculation, e.g. microcirculatory clotting, cellular dysoxia, cell stunning (194). The treatment for this latter stage is unclear.

Two key areas are developing in the management of the hemodynamics of severe sepsis (194). One focus is on improving tissue oxygenation, both in the macro and microcirculation. Hence, tissue oxygenation end points, such as central venous oxygen saturation $\left(\mathrm{ScvO}_{2}\right)$, tissue oxygenation $\left(\mathrm{StO}_{2}\right)$ and lactate are taking on increased importance. The second focus of treatment centers on improving macrocirculation, moving toward measuring flow rather than pressure.

\section{A. Improving tissue oxygenation}

1. We suggest continuous measurement of tissue oxygenation vs. intermittent measurement (grade 2D).

Rationale. Central venous catheter use is associated with trends in mortality reduction as long as resuscitation bundle compliance exists (142). Continuous measurement of tissue oxygenation contributes to earlier recognition of changes in patient status and treatment 
efficacy in relation to periodic central line sampling. While the cost of continuous $\mathrm{ScvO}_{2}$ monitoring technology is higher than the cost of processing intermittent samples, several factors mitigate this disadvantage. These factors include reduced nursing time with continuous measurement, avoidance of clinician exposure to blood and improved ability to detect changes with continuous monitoring. Preliminary data suggest continuous $\mathrm{ScvO}_{2}$ monitoring may be more cost-effective for institutions overall (195).

2. We suggest consideration of non-invasive monitoring of tissue oxygenation when central venous access is less desired or unavailable (grade 2D).

Rationale. Newer technology allows non-invasive monitoring of tissue (peripheral vascular) oxygenation, specifically near infrared spectroscopy. $\mathrm{StO}_{2}$ is a continuous, transcutaneous measurement of tissue oxygenation via an electrode proximal to the thumb. Data suggest that $\mathrm{StO}_{2}$ may be a better marker than gross hemodynamics at revealing information regarding the microcirculation. Donati et al. showed that $\mathrm{StO}_{2}$ was responsive to identifying the impact of activated protein C, unlike gross measures of hemodynamics (196). Leone et al. indicated $\mathrm{StO}_{2}$ values below 78\% were correlated with lower survival rates (197). However, both of these studies were limited in both sample size and phase of sepsis utilized.

One of the main values of $\mathrm{StO}_{2}$ is its non-invasive application. Situations involving severe sepsis in which central venous catheter insertion is less desirable or inappropriate should be considered for $\mathrm{StO}_{2}$ monitoring. $\mathrm{StO}_{2}$ measurement can be obtained via an easy-to-use, transcutaneous application. While not definitive at this point, some data suggest that belownormal values may identify sepsis earlier (198), predict development of organ dysfunction (199), and serve as an $\mathrm{ScvO}_{2}$ alternative. However, outcome data using $\mathrm{StO}_{2}$ is still lacking. While promising, the literature remains unclear on how best to use $\mathrm{StO}_{2}$ in severe sepsis. 
3. We suggest consideration of point-of-care lactate values as a quicker alternative to traditional serum lactate as appropriate (grade 2D).

Rationale. Degree of blood lactate elevation correlates directly with morbidity and mortality in severe sepsis $(200,201)$, and high correlation has also been shown between central laboratory and point-of-care values. Early detection of elevated lactate facilitates early recognition and treatment in addition to being a more accurate triage tool than vital signs (201). Howell et al. indicated lactate would predict 28-day outcome better than traditional monitoring parameters such as blood pressure (201). Elevated lactate, specifically type A lactic acidosis, is one of the few indicators of hypoxia. Lactate can be at dangerous levels while normal monitoring parameters like vital signs remain within normal limits. Using pointof-care lactate as the catalyst to implementation of a sepsis algorithm an $18 \%$ reduction in mortality and four-day reduction in length of stay was achieved $(202,203)$. We suggest that point-of-care lactate measurement be considered to accelerate the clinician's knowledge of the danger a patient faces if serum lactate laboratory results exceed turnaround times of approximately one hour $(200,201)$.

\section{B. Improving macrocirculation}

1. We suggest use of stroke volume or stroke volume variation (SVV) as a key resuscitation measure, independent of whether a central line can be placed (grade 2D).

Rationale. Improving blood flow is the key strategy during resuscitation. Secondary markers such as blood pressure, CVP, and PCWP have been used as surrogates for blood flow (204). However, these parameters have been shown to be inaccurate and slow to change. 
More direct measures of blood flow, for example, stroke volume, offer more precise evaluation of the effectiveness of therapies such as fluids and inotropes (194). Although CVP is recommended as a resuscitation endpoint in the SSC Guidelines (4), clinicians must be aware of the limitations of treating right atrial pressure. Independent of sepsis, it is recognized that the usefulness of CVP is limited in clinical decisions regarding fluid management, due to inability to predict blood volume or preload in response to fluid resuscitation (205). Since CVP was in both the intervention group and the control group in the original early goaldirected therapy paper (158), one could argue that it was the added advantage of the $\mathrm{ScvO}_{2}$ in the intervention group that was associated with improved outcomes, not improving CVP. The parameter that changes before $\mathrm{ScvO}_{2}$ is stroke volume. In the perioperative setting, measuring stroke volume has clearly shown to improve patient outcome $(183,206-213)$. Stroke volume optimization (SVO) has been shown to be a much better metric of preload responsiveness compared to CVP, blood pressure and urine output. Even though data from the pulmonary artery catheter enables computation of a stroke volume estimate $(\mathrm{CO} / \mathrm{HR})$, more direct measurements of stroke volume are made possible by such innovations as the esophageal Doppler, non-invasive Doppler and pulse contour techniques. A growing body of literature supports the efficacy of SVO and SVV in sepsis $(214,215)$. While the theoretical principle is clear, outcome studies using stroke volume and SVV for patients with sepsis are ongoing.

2. We suggest insertion of a peripherally-inserted central catheter (PICC) in the event that subclavian central venous access cannot be obtained in patients with severe sepsis who meet the criteria for central line placement (grade 2D).

Rationale. Enhanced catheter flow rates, hemodynamic monitoring, and power injection capability are among some of the most recent developments in PICC use. Additional 
advantages include the insertion capability of advanced practice nurses or trained registered nurses. CVP accuracy has been found to be similar when compared with a traditional central venous catheter (216). However, the ability of PICC to allow for $\mathrm{ScvO}_{2}$ measurement is perhaps its most distinct advantage compared to peripheral lines.

\section{OTHER SUPPORTIVE NURSING CARE}

All critically ill patients, including the patient with severe sepsis, should receive accepted standards of fundamental nursing care. While no evidence specifically links many components of fundamental nursing care to the outcomes of patients with severe sepsis, these aspects of care have been shown to improve outcomes in all critically ill patients and a brief review follows. Many have been shown to reduce the risk of infection and therefore may decrease the risk of sepsis.

\section{A. Nutrition therapy}

Critical illness is often associated with a hypermetabolic state and increased nutritional requirements. Malnutrition in the critically ill is not uncommon (217) and is associated with an increase in morbidity and mortality (218). Although the traditional emphasis of nutritional support has been on caloric intake this has evolved to nutrition as a therapy where the metabolic response to stress may be attenuated, cellular injury may be prevented, and the immune response may be favorably modulated (219). Extensive guidelines provide recommendations for nutrition therapy for the critically ill $(217,220-222)$ and have been shown to improve the provision of enteral nutrition (223). Consequently, incorporating such guidelines into the care of patients with severe sepsis is recommended.

1. We suggest early enteral nutrition (initiated within 24-48 hours of ICU admission) (grade 
Rationale. Critical illness is associated with intestinal mucosal atrophy with loss of barrier function and potential microbial translocation. Early initiation of enteral nutrition may prevent intestinal mucosal atrophy. In addition, enteral nutrition can reduce the need for parenteral nutrition with substances that enhance bacterial growth (e.g. lipid emulsions) and as such reduce the risk of CR-BSI. Enteral nutrition, when compared to parenteral nutrition, has been shown to reduce the risk for infectious complications by $30-40 \%(224,225)$. A similar reduction has also been found with early, compared to delayed enteral nutrition (226). Despite the benefits of enteral nutrition, caution should be exercised in patients not yet resuscitated from septic shock where gut perfusion may be compromised. Caution should also be taken in using immune-modulating enteral formulations (supplemented with agents, such as arginine, glutamine, nucleic acid, omega-3 fatty acids, and antioxidants) in patients with severe sepsis (219).

\section{B. Eye care}

1. We suggest daily assessment of the ability of the ICU patient to maintain eyelid closure (grade 2D).

2. We suggest at least weekly assessment of ICU patients for iatrogenic ophthalmologic complications and prompt referral for suspicion of these (grade 2D).

3. We recommend the maintenance of eyelid closure for intensive care patients (grade 1B).

Rationale. These recommendations apply to all critically ill patients, including those with severe sepsis. Many critically ill patients have altered levels of consciousness, which may 
impact on the protective mechanisms of the eye resulting in an increased risk of injury such as corneal dehydration, abrasion, perforation and infection (227). The incidence of corneal abrasion varies widely but may affect up to $60 \%$ of intensive care patients (228-230). A variety of eye care methods have been described and tested with evidence that a range of methods reduce the incidence of corneal damage (227, 230-232), but there is insufficient evidence to recommend any single method as being superior. Daily assessment of the patient's ability to maintain eyelid closure should be undertaken. Nurses could also be trained to perform weekly ophthalmologic examinations, using fluorescein drops and a cobalt blue pen torch (231), as early detection of iatrogenic ophthalmologic complications will facilitate timely referral to ophthalmology specialists and potentially improve patient outcomes.

\section{Pressure ulcer prevention and management}

1. We recommend the implementation of a pressure ulcer prevention and treatment bundle including risk assessment, skin assessment, nutrition, repositioning and use of support surfaces (grade 1D).

Extensive recommendations for both the prevention and treatment of pressure ulcers have been developed and contain specific recommendations for the critically ill $(233,234)$.

Critically ill patients are susceptible to the development of pressure ulcers because of increased risks such as impaired circulation, use of inotropic drugs, decreased mobility, disturbed sensory perception, and underlying disease processes (235). The patient with severe sepsis often experiences significant hemodynamic compromise and therefore is particularly at risk for the development of pressure ulcers. Although variable, the incidence of pressure ulcers in the critically ill has been reported to be between $5.2-20 \%$ with a prevalence rate of $14.4 \%$ (236). While not all pressure ulcers can be avoided, strategies can be used to reduce 
the incidence. Assessment of risk factors is one such strategy, but the predictive validity of risk assessment scales is problematic and there is little evidence for a valid risk assessment tool in the critically ill (237-239).

Special considerations related to prevention include: use of special support surfaces for patients who cannot be turned regularly; slow, gradual turns, while assessing patient tolerance for the procedure, may reduce the effect on hemodynamic and oxygenation compromise; more frequent small shifts in position will allow some reperfusion in patients who cannot tolerate major shifts in body position; lateral rotation therapy may be considered; patients receiving lateral rotation therapy will continue to require regular turns and skin assessment (233). Shear injury is a potential consequence of lateral rotation therapy. Bolster pads may prevent sacral shearing in these patients (233).

Special considerations related to management of pressure areas in severe sepsis patients include: positioning to minimize pressure on affected area; inspect pressure ulcer and surrounding area with every dressing change; if there is evidence of shear injury change lateral rotation support to a support system with improved pressure redistribution, shear reduction, microclimate control, and without rotation (234). Documentation of pressure ulcer staging and treatment is essential for continuity of care; however, two recent systematic reviews revealed that a multitude of pressure ulcer grading scales currently exist, with insufficient evidence to recommend a specific classification system $(240,241)$. The role of ICU mobilization of critically ill patients has also been advocated for the promotion of skin integrity as well as prevention of complications of bedrest (242). 


\section{PEDIATRICS}

Sepsis remains an urgent issue among pediatric patients. Worldwide, it affects a large pediatric population and is the most common cause of death in infants and children (243). Severe sepsis accounts for more than 4,300 deaths annually (244).

Sepsis tends to peak at two primary times in the child's life and correspond to significant times in the maturity of the immune system (245). The first peak is in the neonate with an incidence of 4.3 per 1000 neonates. Sixty percent of cases occur in the first five days with an overall mortality of approximately $20 \%$. The second peak is at about two years of age.

In 2002, the International Pediatric Sepsis Consensus Conference participants modified the adult SIRS criteria and associated definitions for children (246). SIRS is defined as the presence of at least two of the following conditions, one of which must be abnormal temperature or leukocyte count. The conditions include:

- $\quad$ core temperature of $>38.5^{\circ} \mathrm{C}$ or $<36^{\circ} \mathrm{C}$

- tachycardia, defined as a mean heart rate $>2$ standard deviations (SD) above normal for age in the absence of external stimulus, chronic drugs, or painful stimuli; or otherwise unexplained persistent elevation over a 30-minute to 4-hour time period, or

for children $>1$ year of age, bradycardia, defined as a mean heart rate $<10^{\text {th }}$ percentile for age in the absence of external vagal stimulus, $\beta$-blocker drugs, or congenital heart disease; or otherwise unexplained persistent depression over a 30-minute time period

- mean respiratory rate $>2 \mathrm{SD}$ above normal for age or mechanical ventilation for an acute process not related to underlying neuromuscular disease or general anesthesia

- leukocyte count elevated or depressed for age (not secondary to chemotherapyinduced leukopenia) or the presence of $>10 \%$ immature neutrophils (246).

An infection is defined as a suspected or proven (by positive culture, tissue stain, or 
polymerase chain reaction test) infection caused by any pathogen or a clinical syndrome associated with a high probability of infection. Evidence of infection includes positive findings on clinical exam, imaging, or laboratory tests (e.g. white blood cells in a normally sterile body fluid, perforated viscus, chest radiograph consistent with pneumonia, petechial or purpural rash, or purpura fulminans) (246).

Sepsis is defined as SIRS in the presence of or as a result of a suspected or proven infection (246). Severe sepsis is defined as sepsis plus one of the following:

- cardiovascular organ dysfunction;

- acute respiratory distress syndrome;

- $\geq 2$ other organ dysfunctions (respiratory, renal, neurologic, hematologic, hepatic) (246).

There are developmental differences in the hemodynamic response to sepsis in children when compared to adults. A decrease in cardiac output is associated with mortality in children with septic shock (247). Based on this developmental difference, reaching a therapeutic end point of a cardiac index $(\mathrm{CI})$ of $3.3-6.0 \mathrm{~L} / \mathrm{min} / \mathrm{m}^{2}$ may result in better survival (247). In addition, oxygen delivery is the major determinant of oxygen consumption in children as opposed to oxygen extraction, so the therapeutic endpoint of an oxygen consumption of greater than 200 $\mathrm{mL} / \mathrm{min} / \mathrm{m} 2$ may also be associated with a better outcome (247).

\section{A. Fluid resuscitation}

1. We suggest intravascular volume expansion is achieved with fluid boluses of $20 \mathrm{~mL} / \mathrm{kg}$ of isotonic saline or colloids, as identified in the SSC guidelines (4) (grade 2C). 
Rationale. As much as $200 \mathrm{~mL} / \mathrm{kg}$ may be administered in the first hour of resuscitation, although the average is $40-60 \mathrm{~mL} / \mathrm{kg}$. Fluid replacement should be directed towards perfusion, central venous pressure, echocardiographic determination of end-diastolic volume, pulmonary capillary wedge pressure/end-diastolic volume and cardiac output (247).

\section{B. Vasopressors/inotropes}

1. We suggest vasopressors/inotropes are implemented if clinical signs of shock continue in spite of adequate volume replacement, as identified in the SSC guidelines (4) (grade 2C).

Rationale. An important point to remember about these medications is that since septic shock is a dynamic process, the medication used and the infusion dose may require adjustment over time, based on the need to maintain organ perfusion as well as the pharmacokinetics and the pharmacodynamics of the child's response to the drug. Perfusion and function of the liver and kidney are often changed in the child with severe sepsis, causing changes in the medication pharmacokinetics with higher concentrations observed. Therefore standard infusion doses may need to be adjusted.

For ongoing therapy, the use of inotropes, vasopressors, and vasodilators will differ. Dobutamine may be useful for pediatric patients with low cardiac output states (248). Vasopressin can increase MAP, SVR, and urine output in children with vasodilatory septic shock and lack of response to catecholamines. However, the safety and effectiveness of vasopressin in children with septic shock have not been well demonstrated (249). Occasionally, children alter their hemodynamic requirements from vasopressor to inotrope or vice versa (247). Table 6 presents a summary of the pharmacologic therapy used in the treatment of pediatric septic shock (250). 


\section{Steroids}

1. We suggest hydrocortisone therapy may be generally reserved for the child with catecholamine-resistant shock and suspected or proven adrenal insufficiency, as identified in the SSC guidelines (4) (grade 2C).

Rationale. Hydrocortisone therapy may be lifesaving in the child with sepsis, but its use is generally reserved for the child with catecholamine-resistant shock and suspected or proven adrenal insufficiency. A recent study examined the issue of neuroendocrine dysfunction in children, including adrenal insufficiency and found a markedly higher incidence of multiple neurohormonal dysfunctions in children with sepsis (249). These findings suggest both that neuroendocrine deficiency is common in pediatric sepsis and that many neurohormonal responses may be affected (249). Generally, adrenal insufficiency in the case of catecholamineresistant shock is assumed at a random total cortisol level of $<18 \mu \mathrm{g} / \mathrm{dL}$ ( $496 \mathrm{nmol} / \mathrm{L}$ ). Dose recommendations for treatment of shock are $50 \mathrm{mg} / \mathrm{kg}$ followed by the same dose as a 24-hour infusion $(248,251)$. Although not responsible for ordering steroids, it is essential that nurses work collaboratively to recognize the presence of refractory shock and initiate both timely measurement of cortisol levels and administration of hydrocortisone therapy where appropriate.

\section{Sedation/analgesia}

1. We suggest that critically ill pediatric patients receive goal-directed therapy for sedation and analgesia (grade 2D).

Rationale. Pain causes energy expenditure and increases oxygen demand. Nurses play a key role in addressing this issue. Sedation and analgesia are commonly used in pediatric patients with severe sepsis to relieve pain, support mechanical ventilation and to reduce oxygen 
demand (252). The first step to initiating sedation and analgesia is to rule out physiological causes of agitation including hypoxemia, pain, hypercapnea and cerebral hypoperfusion. Addressing the child's comfort by providing analgesia and sedation and decreasing restlessness helps to preserve oxygen for use by major organs (253). There are no data supporting any specific medications; therefore, drugs and dosages are based on the child's response. Therapy should be goal-directed using a validated scale to determine the child's level of comfort (254). In addition, comfort measures including appropriate positioning, gentle touch, and managing the environment to decrease or eliminate noxious stimuli are essential.

\section{E. Therapeutic end points}

1. We recommend the use of therapeutic end points to guide interventions for the pediatric patient with severe sepsis and septic shock (grade 1D).

Rationale. Therapeutic end points have been established for both initial resuscitation and ongoing treatment. The goals for the first hour of resuscitation remain focused on airway, breathing, and circulation. The therapeutic endpoints include a capillary refill time $<2$ seconds, normal pulses, no differential between peripheral and central pulses, warm extremities, urine output $>1 \mathrm{~mL} / \mathrm{kg} / \mathrm{hr}$, normal mental status and normal glucose, ionized calcium and blood pressure for age (247).

Once the initial resuscitation has taken place, attention is required to verify the effects of hypovolemia and cardiac and vascular dysfunction. The goals of stabilization are: normal perfusion, a perfusion pressure normal for age, superior vena cava or mixed venous oxygen saturation of $>70 \%$; and $\mathrm{CI}>3.3 \mathrm{~L} / \mathrm{min} / \mathrm{m}^{2}$ and $<6.0 \mathrm{~L} / \mathrm{min} / \mathrm{m}^{2}$ (255). The therapeutic endpoints are a capillary refill time $<2$ seconds, normal pulses with no difference between peripheral and central pulses, warm extremities, urine output $>1 \mathrm{~mL} / \mathrm{kg} / \mathrm{hr}$, normal mental status, $\mathrm{CI}>3.3$ 
$\mathrm{L} / \mathrm{min} / \mathrm{m}^{2}$ and $<6.0 \mathrm{~L} / \mathrm{min} / \mathrm{m}^{2}$ and superior vena cava or mixed venous oxygen saturation $>70 \%$. Cardiac index is augmented by increasing preload (247). Monitoring includes heart rate, oxygen saturation, blood pressure, temperature, urine output, central venous pressure, pulmonary artery pressure, cardiac output, glucose, and calcium (247). 


\section{SUMMARY AND FUTURE DIRECTIONS}

This document provides a summary of the evidence that currently exists to underpin the nursing care of the patient with severe sepsis. Several limitations relate to the document including the time and resources available to develop these recommendations and the lack of evidence that exists in many areas of care. While a concerted effort was made to summarize the evidence from existing research and guidelines and reach consensus as to the level of support for nursing care considerations, much of the work was undertaken by small groups of 2-3 authors, with discussion and consensus by the entire author group then achieved through email discussion. Although this provided an opportunity for all authors to raise concerns regarding grading of recommendations, the depth of discussion was confined to that possible by email.

As outlined above, multiple areas of nursing care either have no evidence to inform practice, or the level of evidence is confined to expert opinion. Research to identify the most appropriate nursing interventions for severe sepsis patients is urgently required. Areas that are particularly needed include recognition of deterioration and diagnosis of sepsis, type and effect of early resuscitative measures, effective methods of hemodynamic assessment and support, type and effect of supportive care such as nutrition therapy, pressure ulcer prevention and management and mouth and eye care and application of these interventions to the

pediatric severe sepsis patient. Identification of new evidence should inform the ongoing care of the severely septic patient and as such, this document represents an ongoing process. 


\section{REFERENCES}

1. Angus DC, Linde-Zwirble WT, Lidicker J, et al: Epidemiology of severe sepsis in the United States: analysis of incidence, outcome, and associated costs of care. Crit Care Med 2001; 29:1303-1310

2. Australasian Resuscitation in Sepsis Evaluation (ARISE) Investigators and the Australian and New Zealand Intensive Care Society (ANZICS) Adult Patient Database (APD) Management Committee: The outcome of patients with sepsis and septic shock presenting to emergency departments in Australia and New Zealand. Crit Care Resusc 2007; 9:8-18

3. Dellinger RP, Carlet JM, Masur H, et al: Surviving Sepsis Campaign guidelines for management of severe sepsis and septic shock. Crit Care Med 2004; 32:858-873

4. Dellinger RP, Levy MM, Carlet JM, et al: Surviving Sepsis Campaign: international guidelines for management of severe sepsis and septic shock. Crit Care Med 2008; 36:296-327

5. Guyatt G, Gutterman D, Baumann MH, et al: Grading strength of recommendations and quality of evidence in clinical guidelines: report from an american college of chest physicians task force. Chest 2006; 129:174-181

6. Prior M, Guerin M, Grimmer-Somers K: The effectiveness of clinical guideline implementation strategies - a synthesis of systematic review findings. J Eval Clin Pract 2008; 14:888-897

7. Safdar N, Abad C: Educational interventions for prevention of healthcare-associated infection: A systematic review. Crit Care Med 2008; 36:933-940

8. Eggimann P, Pittet D: Infection control in the ICU. Chest 2001; 120:2059-2093

9. Jarvis WR: The United States approach to strategies in the battle against healthcareassociated infections, 2006: transitioning from benchmarking to zero tolerance and clinician accountability. $J$ Hosp Infect 2007; 65:3-9

10. Yokoe DS, Mermel LA, Anderson DJ, et al: A compendium of strategies to prevent healthcare-associated infections in acute care hospitals. Infect Control Hosp Epidemiol 2008; 29:S12-21

11. Harbarth S, Sax H, Gastmeier P: The preventable proportion of nosocomial infections: an overview of published reports J Hosp Infect 2003; 54:258-266

12. Berenholtz SM, Pronovost PJ, Lipsett PA, et al: Eliminating catheter-related bloodstream infections in the intensive care unit. Crit Care Med 2004; 32:2014-2020

13. Pronovost P, Needham D, Berenholtz S, et al: An intervention to decrease catheterrelated bloodstream infections in the ICU. N Engl J Med 2006; 355:2725-2732

14. Condon RE, Schulte WJ, Malangoni MA, et al: Effectiveness of a surgical wound surveillance program. Arch Surg 1983; 118:303-307

15. Cruse P: Wound infection surveillance. Rev Infect Dis 1981; 4:734-737

16. Cruse PJ, Foord R: The epidemiology of wound infection: a 10-year prospective study of 62,939 wounds. Surg Clin North Am 1980; 60:27-40

17. Gastmeier P, Geffers C: Prevention of catheter-related bloodstream infections: analysis of studies published between 2002 and 2005. J Hosp Infect 2006; 64: 326-335

18. Haley RW, Culver DH, White JW, et al: The efficacy of infection surveillance and control programs in preventing nosocomial infections in US hospitals. Am J Epidemiol 1985; 121:182-205

19. Sykes PK, Brodribb RK, McLaws M-L, et al: When continuous surgical site infection surveillance is interrupted: the Royal Hobart Hospital experience. Am J Infect Control 2005; 33:422-427 
20. Boyce JM, Pittet D: Guideline for hand hygiene in health-care settings:

Recommendations of the Healthcare Infection Control Practices Advisory Committee and the HIPAC/SHEA/APIC/IDSA Hand Hygiene Task Force. Am J Infect Control 2002; 30:S1-S46

21. Pratt RJ, Petlowe CM, Wilson JA, et al: EPIC2: National evidence-based guidelines for preventing healthcare-assosciated infections in NHS hospitals in England. $J$ Hosp Infect 2007; 65:S1-S64

22. Clark L, Smith W, Young L: Protective clothing: principles and guidance. London: Infection Control Nurses Association; 2002

23. Corona A, Raimondi F: Prevention of nosocomial infection in the ICU setting. Minerva Anestesiologica 2004; 70:329-337

24. Safdar N, Dezfulian C, Collard HR, et al: Clinical and economic consequences of ventilator-associated pneumonia: A systematic review. Crit Care Med 2005; 33:21842193

25. Cook D, Walter S, Cook R, et al: Incidence of and risk factors for ventilator-associated pneumonia in critically ill patients. Ann Intern Med 1998; 129:433-440

26. Tejerina E, Frutos-Vivar F, Restrepo MI, et al: Incidence, risk factors, and outcome of ventilator-associated pneumonia. J Crit Care 2006; 21:56-65

27. Warren DK, Shukla SJ, Olsen MA, et al: Outcome and attributable cost of ventilatorassociated pneumonia among intensive care unit patients in a suburban medical center. Crit Care Med 2003; 31:1312-1317

28. Lai K, Baker S, Fontecchio S: Impact of a program of intensive surveillance and interventions targeting ventilated patients in the reduction of ventilator-associated pneumonia and its cost-effectiveness. Infect Control Hosp Epidemiol 2003; 24:859-863

29. Zack JE, Garrison T, Trovillion E, et al: Effect of an education program aimed at reducing the occurrence of ventilator-associated pneumonia. Crit Care Med 2002; 30:2407-2412

30. Lorente L, Blot S, Rello J: Evidence on measures for the prevention of ventilatorassociated pneumonia. European Respiratory Journal 2007; 30:1193-1207

31. Wip C, Napolitano L: Bundles to prevent ventilator-associated pneumonia: how valuable are they? Curr Opin Infect Dis 2009; 22:159-166

32. Muscedere J, Dodek P, Keenan S, et al: Comprehensive evidence-based clinical practice guidelines for ventilator-associated pneumonia: diagnosis and treatment. J Crit Care 2008; 23:138-147

33. Huxley EJ, Viroslav J, Gray WR, et al: Pharyngeal aspiration in normal adults and patients with depressed consciousness. Am J Med 1978; 64:564-568

34. Ibáñez J, Peñafiel A, Raurich JM, et al: Gastroesophageal reflux in intubated patients receiving enteral nutrition: effect of supine and semirecumbent positions. JPEN, Journal of parenteral and enteral nutrition 1992; 16:419-422

35. Orozco-Levi M, Torres A, Ferrer M, et al: Semirecumbent position protects from pulmonary aspiration but not completely from gastroesophageal reflux in mechanically ventilated patients. Am J Respir Crit Care Med 1995; 152:1387-1390

36. Torres A, Serra-Batlles J, Ros E, et al: Pulmonary aspiration of gastric contents in patients receiving mechanical ventilation: the effect of body position. Ann Intern Med 1992; 116:540-543

37. Drakulovic MB, Torres A, Bauer TT, et al: Supine body position as a risk factor for nosocomial pneumonia in mechanically ventilated patients: a randomised trial. Lancet 1999; 354:1851-1858 
38. Fernández-Crehuet R, Díaz-Molina C, de Irala J, et al: Nosocomial infection in an intensive-care unit: identification of risk factors. Infect Control Hosp Epidemiol 1997; 18:825-830

39. Kollef MH: Ventilator-associated pneumonia. A multivariate analysis. JAMA 1993; 270:1965-1970

40. Song H, Liu J, Gao S, et al: Clinical investigation on the compliance and the validity of ventilator bundle. Zhongguo Wei Zhong Bing Ji Jiu Yi Xue 2009; 21:660-663

41. van Nieuwenhoven CA, Vandenbroucke-Grauls C, van Tiel FH, et al: Feasibility and effects of the semirecumbent position to prevent ventilator-associated pneumonia: a randomized study. Crit Care Med 2006; 34:396-402

42. Cason C, Tyner T, Saunders S, et al: Nurses' implementation of guidelines for ventilator-associated pneumonia from the Centers for Disease Control and Prevention.

Am J Crit Care 2007; 16:28-36

43. Dezfulian C, Shojania K, Collard HR, et al: Subglottic secretion drainage for preventing ventilator-associated pneumonia: a meta-analysis. Am J Med 2005; 118:11-18

44. Kollef MH, Afessa B, Anzueto A, et al: Silver-coated endotracheal tubes and incidence of ventilator-associated pneumonia: the NASCENT randomized trial. JAMA 2008; 300:805-813

45. Rello J, Kollef M, Diaz E, et al: Reduced burden of bacterial airway colonization with a novel silver-coated endotracheal tube in a randomized multiple-center feasibility study. Crit Care Med 2006; 34:2766-2772

46. Poelaert J, Depuydt P, De Wolf A, et al: Polyurethane cuffed endotracheal tubes to prevent early postoperative pneumonia after cardiac surgery: a pilot study. $J$ Thoracic Cardiovasc Surg 2008; 135:771-776

47. Rello J, Sonora R, Jubert P, et al: Pneumonia in intubated patients: Role of respiratory airway care. Am J Respir Crit Care Med 1996; 154:111-115

48. Niël-Weise B, Wille J, van den Broek P: Humidification policies for mechanically ventilated intensive care patients and prevention of ventilator-associated pneumonia: a systematic review of randomized controlled trials. J Hosp Infect 2007; 65:285-291

49. Davis KJ, Evans SL, Campbell RS, et al: Prolonged use of heat and moisture exchangers does not affect device efficiency or frequency rate of nosocomial pneumonia. Crit Care Med 2000; 28:1412-1418

50. Thomachot L, Leone M, Razzouk K, et al: Randomized clinical trial of extended use of a hydrophobic condenser humidifier: 1 vs. 7 days. Crit Care Med 2002; 30:232-237

51. Tsai TP, Lin YT, Wang YC, et al: Ventilator-Associated Pneumonia and Frequency of Circuit Changes. Chest 2004; 126:898S

52. Thomson L, Morton R, Cuthbertson S, et al: Tracheal suctioning of adults with an artificial airway. Best Practice 2000; 4:1-6

53. Celik S, Elbas N: The standard of suction for patients undergoing endotracheal intubation. Intensive Crit Care Nurs 2000; 16:191-198

54. Day K, Haub N, Betts H, et al: Hyperglycemia is associated with morbidity in critically ill children with meningococcal sepsis. Pediatr Crit Care Med 2008; 9:636-640

55. Rolls K, Smith K, Jones P, et al. Suctioning an adult with a tracheal tube. NSW Health Statewide Guidelines for Intensive Care. In: Health N, editor.: NSW Health; 2007

56. Wood CJ: Endotracheal suctioning: a literature review. Intensive Crit Care Nurs 1998; 14:124-136

57. Pedersen C, Rosendahl-Nielsen M, Hjermind J, et al: Endotracheal suctioning of the adult intubated patient-What is the evidence? Intensive Crit Care Nurs 2009; 25:21-30

58. Craven D, Driks M: Nosocomial pneumonia in the intubated patient. Semin Respir Infect 1987; 2:20-33 
59. Torres A, el-Ebiary M, González J, et al: Gastric and pharyngeal flora in nosocomial pneumonia acquired during mechanical ventilation. Am Rev Respir Dis 1993; 148:352357

60. Vallés J, Artigas A, Rello J, et al: Continuous aspiration of subglottic secretions in preventing ventilator-associated pneumonia. Ann Intern Med 1995; 122:179-186

61. Abele-Horn M, Dauber A, Bauernfeind A, et al: Decrease in nosocomial pneumonia in ventilated patients by selective oropharyngeal decontamination (SOD). Intensive Care Med 1997; 23:187-195

62. Johanson WG, Seidenfeld JJ, de los Santos R, et al: Prevention of nosocomial pneumonia using topical and parenteral antimicrobial agents. Am Rev Respir Dis 1988; 137:265-272

63. Berry A, Davidson P. Consensus-based clinical guideline for the provision of oral care for the critically ill adult. NSW Health; 2007

64. Fields L: Oral care intervention to reduce incidence of ventilator-associated pneumonia in the neurologic intensive care unit. J Neurosci Nurs 2008; 40:291-298

65. Garcia R, Jendresky L, Colbert L, et al: Reducing ventilator-associated pneumonia through advanced oral-dental care: a 48-month study. Am J Crit Care 2009; 18:523-532

66. Munro CL, Grap MJ, Jones DJ, et al: Chlorhexidine, toothbrushing, and preventing ventilator-associated pneumonia in critically ill adults. Am J Crit Care 2009; 18:428437

67. Weireter L, Collins J, al. e: Impact of a monitored program of care on incidence of ventilator-associated pneumonia: results of a longterm performance-improvement project. J Am Coll Surg 2009; 208:700-704; discussion 704-705.

68. Ross A, Crumpler J: The impact of an evidence-based practice education program on the role of oral care in the prevention of ventilator-associated pneumonia. Intensive Crit Care Nurs 2007; 23:132-136

69. Blot S, Vandijck D, Labeau S: Oral care of intubated patients. Clinical Pulmonary Medicine 2008; 15:153-160

70. Grap MJ, Munro CL, Ashtiani B, et al: Oral care interventions in critical care: Frequency and documentation. Am J Crit Care 2003; 12:113-118

71. Jones DJ, Munro CL: Oral care and the risk of bloodstream infections in mechanically ventilated adults: A review. Intensive Crit Care Nurs 2008; 24:152-161

72. Munro CL, Grap MJ: Oral health and care in the intensive care unit: State of the science. Am J Crit Care 2004; 13:25-33

73. Choo A, Delac DM, Messer LB: Oral hygiene measures and promotion: Review and considerations. Aust Dent J 2001; 46:166-173

74. Moshrefi A: Chlorhexidine. J West Soc Periodontol Periodontal Abstr 2002; 50:5-9

75. Fourrier F, Cau-Pottier E, Boutigny H, et al: Effects of dental plaque antiseptic decontamination on bacterial colonization and nosocomial infections in critically ill patients. Intensive Care Med 2000; 26:1239-1247

76. DeRiso AJ, Ladowski JS, Dillon TA, et al: Chlorhexidine gluconate $0.12 \%$ oral rinse reduces the incidence of total nosocomial respiratory infection and nonprophylactic systemic antibiotic use in patients undergoing heart surgery. Chest 1996; 109:

77. Chan EY, Ruest A, Meade MO, et al: Oral decontamination for prevention of pneumonia in mechanically ventilated adults: systematic review and meta-analysis. $\mathrm{Br}$ Med J 2007; 334:889-893

78. Chlebicki MP, Safdar N: Topical chlorhexidine for prevention of ventilator-associated pneumonia: A meta-analysis. Crit Care Med 2007; 35:595-602

79. Tantipong H, Morkchareonpong C, Jaiyindee S, et al: Randomized controlled trial and meta-analysis of oral decontamination with $2 \%$ chlorhexidine solution for the 
prevention of ventilator-associated pneumonia. Infect Control Hosp Epidemiol 2008; 29:131-136

80. Abidia RF: Oral care in the intensive care unit: a review. J Contemp Dent Pract 2007; 8:76-82.

81. Rello J, Koulenti D, Blot S, et al: Oral care practices in intensive care units: a survey of 59 European ICUs. Intensive Care Med 2007; 33:1066-1070

82. Galpern D, Guerrero A, Tu A, et al: Effectiveness of a central line bundle campaign on line-associated infections in the intensive care unit. Surgery 2008; 144:492-495

83. Tsuchida T, Makimoto K, Toki B, et al: The effectiveness of a nurse-initiated intervention to reduce catheter-associated bloodstream infections in an urban acute hospital: An intervention study with before and after comparison. Int J Nurs Stud 2007; 44:1324-1333

84. Carrer S, Bocchi A, Bortolotti M, et al: Effect of different sterile barrier precautions and central venous catheter dressing on the skin colonization around the insertion site. Minerva Anestesiologica 2005; 71:197-206

85. Hu KK, Lipsky BA, Veenstra DL, et al: Using maximal sterile barriers to prevent central venous catheter-related infection: A systematic evidence-based review. Am J Infect Control 2004; 32:142-146

86. Marschall J, Mermel LA, Classen D, et al: Strategies to prevent central line-associated bloodstream infections in acute care hospitals. Infect Control Hosp Epidemiol 2008; 29:S22-30

87. Raad II, Hohn DC, Gilbreath BJ, et al: Prevention of central venous catheter-related infections by using maximal sterile barrier precautions during insertion. Infect Control Hosp Epidemiol 1994; 15:231-238

88. Young EM, Commiskey ML, Wilson SJ: Translating evidence into practice to prevent central venous catheterassociated bloodstream infections: A systems-based intervention. Am J Infect Control 2006; 34:503-506

89. Maki DG: Yes, Virginia, aseptic technique is very important: maximal barrier precautions during insertion reduce the risk of central venous catheter-related bacteremia. Infect Control Hosp Epidemiol 1994; 15:227-230

90. Mermel LA, McCormick RD, Springman SR, et al: The pathogenesis and epidemiology of catheter-related infection with pulmonary artery Swan-Ganz catheters: a prospective study utilizing molecular subtyping. Am J Med 1991; 91:197-205S

91. Mimoz O, Pieroni L, Lawrence C, et al: Prospective, randomized trial of two antiseptic solutions for prevention of central venous or arterial catheter colonization and infection in intensive care unit patients. Crit Care Med 1996; 24:1818-1823

92. Small H, Adams D, Casey AL, et al: Efficacy of adding 2\% (w/v) chlorhexidine gluconate to $70 \%(\mathrm{v} / \mathrm{v})$ isopropyl alcohol for skin disinfection prior to peripheral venous cannulation. Infect Control Hosp Epidemiol 2008; 29:963-965

93. Valles J, Fernandez I, Alcaraz D, et al: Prospective randomized trial of 3 antiseptic solutions for prevention of catheter colonization in an intensive care unit for adult patients. Infect Control Hosp Epidemiol 2008; 29:847-853

94. Gillies D, O'Riordan L, Wallen M, et al: Optimal timing for intravenous administration set replacement. Cochrane Database of Systematic Reviews 2005;

95. Avila-Figueroa C, Goldmann DA, Richardson DK, et al: Intravenous lipid emulsions are the major determinant of coagulase-negative staphylococcal bacteremia in very low birth weight newborns. Pediatr Infect Dis J 1998; 17:10-17

96. Crocker KS, Noga R, Filibeck DJ, et al: Microbial growth comparisons of five commercial parenteral lipid emulsions. JPEN, J Parenter Enteral Nutr 1984; 8:391-395 
97. Hanna HA, Raad I: Blood products: a significant risk factor for long-term catheterrelated bloodstream infections in cancer patients. Infect Control Hosp Epidemiol 2001; 22:165-166

98. Jarvis WR, Highsmith AK: Bacterial growth and endotoxin production in lipid emulsion. J Clin Microbiol 1984; 19:17-20

99. Raad I, Hanna HA, Awad A, et al: Optimal frequency of changing intravenous administration sets: is it safe to prolong use beyond 72 hours? Infect Control Hosp Epidemiol 2001; 22:136-139

100. Saiman L, Ludington E, Dawson JD, et al: Risk factors for Candida species colonization of neonatal intensive care unit patients. Pediatr Infect Dis J 2001; 20:1119-1124

101. Hanna H, Benjamin R, Chatzinikolaou I, et al: Long-term silicone central venous catheters impregnated with minocycline and rifampin decrease rates of catheter-related bloodstream infection in cancer patients: a prospective randomized clinical trial. J Clin Oncol 2004; 22:3163-3171

102. León C, Ruiz-Santana S, Rello J, et al: Benefits of minocycline and rifampinimpregnated central venous catheters. A prospective, randomized, double-blind, controlled, multicenter trial. Intensive Care Med 2004; 30:1891-1899

103. Raad I, Darouiche R, Dupuis J, et al: Central venous catheters coated with minocycline and rifampin for the prevention of catheter-related colonization and bloodstream infections. A randomized, double-blind trial. The Texas Medical Center Catheter Study Group. Ann Intern Med 1997; 127:267-274

104. Veenstra DL, Saint S, Saha S, et al: Efficacy of antiseptic-impregnated central venous catheters in preventing catheter-related bloodstream infection: a meta-analysis. JAMA $1999 ; 281: 261-267$

105. Darouiche RO, Raad II, Heard SO, et al: A comparison of two antimicrobialimpregnated central venous catheters. Catheter Study Group. N Engl J Med 1999; 340:1-8

106. Bratzler DW, Houck PM: Antimicrobial prophylaxis for surgery: an advisory statement from the National Surgical Infection Prevention Project. Clin Infect Dis 2004; 38:17061715

107. Anderson DJ, Kaye KS, Classen D, et al: Strategies to prevent surgical site infections in acute care hospitals. Infect Control Hosp Epidemiol 2008; 29:S51-S61

108. Mangram AJ, Horan TC, Pearson ML, et al: Guideline for prevention of surgical site infection. Am J Infect Control 1999; 27:97-132

109. Mishriki SF, Law DJ, Jeffery PJ: Factors affecting the incidence of postoperative wound infection. J Hosp Infect 1990; 16:223-230

110. Moro ML, Carrieri MP, Tozzi AE, et al: Risk factors for surgical wound infections in clean surgery: a multicenter study. Italian PRINOS Study Group. Annali italiani di chirurgia 1996; 67:13-19

111. Winston KR: Hair and neurosurgery. Neurosurgery online 1992; 31:320-329

112. Tanner J, Woodings D, Moncaster K. Preoperative hair removal to reduce surgical site infection. Cochrane Database of Systematic Reviews [serial on the Internet]. 2006; (3):

113. Hamilton HW, Hamilton KR, Lone FJ: Preoperative hair removal. Can J Surg 1977; 20:269-271,274

114. Seropian R, Reynolds BM: Wound infections after preoperative depilatory versus razor preparation. Am J Surg 1971; 121:251-254

115. Terranova A: The effects of diabetes mellitus on wound healing. Plastic Surgical Nursing 1991; 11:20-25

116. Zerr KJ, Furnary AP, Grunkemeier GL, et al: Glucose control lowers the risk of wound infection in diabetics after open heart operations. Ann Thorac Surg 1997; 63:356-361 
117. Latham R, Lancaster AD, Covington JF, et al: The association of diabetes and glucose control with surgical-site infections among cardiothoracic surgery patients. Infect Control Hosp Epidemiol 2001; 22:607-612

118. Hunter JG, Padilla M, Cooper-Vastola S: Late Clostridium perfringens breast implant infection after dental treatment. Ann Plastic Surg 1996; 36:309-312

119. Stuesse DC, Robinson JH, Durzinsky DS: A late sternal wound infection caused by hematogenous spread of bacteria. Chest 1995; 108:1742-1743

120. Velasco E, Thuler LC, Martins CA, et al: Risk factors for infectious complications after abdominal surgery for malignant disease. Am J Infect Control 1996; 24:1-6

121. Tenke P, Kovacs B, Bjerklund Johansen T, et al: European and Asian guidelines on management and prevention of catheter-associated urinary tract infections. Int $J$ Antimicrob Agents 2008; 31:S68-78

122. Wald $\mathrm{H}$, Ma A, Bratzler D, et al: Indwelling urinary catheter use in the postoperative period: analysis of the national surgical infection prevention project data. Arch Surg 2008; 143:551-557

123. Willson M, Wilde M, Webb M, et al: Nursing interventions to reduce the risk of catheter-associated urinary tract infection: part 2: staff education, monitoring, and care techniques. J Wound Ostomy Continence Nurs 2009; 36:137-154

124. Garibaldi RA, Burke JP, Dickman ML, et al: Factors predisposing to bacteriuria during indwelling urethral catheterization. N Engl J Med 1974; 291:215-219

125. Gillespie WA, Lennon GG, Linton KB, et al: Prevention of urinary infection in gynaecology. Br Med J 1964; 2:423-425

126. Kunin CM: Detection, prevention, and management of urinary tract infections. 3 ed. Philadelphia: Lea and Febiger; 1979

127. Gould C, Umscheid C, Agarwal R, et al. Guideline for Prevention of Catheterassociated Urinary Tract Infections. 2009; Available from: http://www.cdc.gov/hicpac/pdf/CAUTI/CAUTIguideline2009final.pdf

128. Warren JW, Platt R, Thomas RJ, et al: Antibiotic irrigation and catheter-associated urinary-tract infections. N Engl J Med 1978; 299:570-573

129. Wong E, Hooton T, Centers for Disease Control. Guideline for prevention of catheterassociated urinary tract infections. 1981 [March 20, 2008]; Available from: http://www.cdc.gov/ncidod/dhqp/gl_catheter_assoc.html

130. Tsuchida T, Makimoto K, Ohsako S, et al: Relationship between catheter care and catheter-associated urinary tract infection at Japanese general hospitals: a prospective observational study. Int J Nurs Stud 2008; 45:352-361

131. Dieckhaus KD, Garibaldi RA. Prevention of catheter-associated urinary tract infections. In: Abrutytn E, Goldmann DA, Scheckler WE, editors. Saunders Infection Control Reference Service. Philadelphia: W.B. Saunders Co; 1998. pp 169-174.

132. Ward V, Wilson J, Taylor L, et al: Preventing hospital-acquired infection: clinical guidelines. London: Public Health Laboratory Service; 1997

133. Garnacho-Montero J, Aldabo-Pallas T, Palomar-Martinez M, et al: Risk factors and prognosis of catheter-related bloodstream infection in critically ill patients: a multicenter study. Intensive Care Med 2008; 34:2185-2193

134. Pettigrew RA, Lang SD, Haydock DA, et al: Catheter-related sepsis in patients on intravenous nutrition: a prospective study of quantitative catheter cultures and guidewire changes for suspected sepsis. Br J Surg 1985; 72:52-55

135. Brundage JF: Interactions between influenza and bacterial respiratory pathogens: implications for pandemic preparedness. Lancet Infect Dis 2006; 6:303-312 
136. Siegel JD, Rhinehart E, Jackson M, et al: 2007 Guideline for isolation precautions: preventing transmission of infectious agents in health care settings. Am J Infect Control 2007; 35:S65-164

137. Levy MM, Fink MP, Marshall JC, et al: 2001 SCCM/ESICM/ACCP/ATS/SIS International Sepsis Definitions Conference. Crit Care Med 2003; 31:1250-1256

138. Kleinpell R: Implementing the Surviving Sepsis Campaign guidelines: implications for nursing care. Advances in Sepsis 2005;4:61-63 2005; 4:61-63

139. Clarke SP, Aiken LH: Failure to rescue: Needless deaths are prime examples of the need for more nurses at the bedside. Am J Nurs 2003; 103:42-47

140. Silber JH, Williams SV, Krakauer H, et al: Hospital and patient characteristics associated with death after surgery. A study of adverse occurrence and failure to rescue. Medical Care 1992; 30:615-629

141. Ferrer R, Artigas A, Levy M, et al: Improvement in process of care and outcome after a multicenter severe sepsis educational program in Spain. JAMA 2008; 299:2294-2303

142. Levy M, Dellinger R, Townsend S, et al: The Surviving Sepsis Campaign: results of an international guideline-based performance improvement program targeting severe sepsis. Crit Care Med 2010; 38:367-374

143. Kleinpell RM: The role of the critical care nurse in the assessment and management of the patient with severe sepsis. Crit Care Nurs Clin North Am 2003; 15:27-34

144. Robson W, Daniels R: The Sepsis Six: helping patients to survive sepsis. Br J Nurs 2008; $17: 16-21$

145. National Patient Safety Agency. Recognising and responding appropriately to early signs of deterioration in hospitalised patients. 2007 [28 December 2009]; Available from: http://www.nrls.npsa.nhs.uk/resources/?entryid45=59834

146. National Institute for Health and Clinical Excellence. Acutely ill patients in hospital: Recognition of and response to acute illness in adults in hospital. 2007 [28 December 2009]; Available from: http://www.nice.org.uk/nicemedia/pdf/CG50FullGuidance.pdf

147. Gao H, McDonnell A, Harrison D, et al: Systematic review and evaluation of physiological track and trigger warning systems for identifying at-risk patients on the ward. Intensive Care Med 2007; 33:667-679

148. McGaughey J, Alderdice F, Fowler R, et al: Outreach and early warning systems (EWS) for the prevention of intensive care admission and death of critically ill adult patients on general hospital wards. Cochrane Database of Systematic Reviews 2007;

149. Patient Safety First Campaign. The 'how to guide' for reducing harm from deterioration. 2008 [28 December 2009]; Available from: http://www.patientsafetyfirst.nhs.uk/ashx/Asset.ashx?path=/How-to-guides-2008-0919/Deterioration\%201.1_17Sept08.pdf

150. Moore L, Jones S, Kreiner L, et al: Validation of a screening tool for the early identification of sepsis. J Trauma 2009; 66:1539-1546

151. Reeves $S$, Lewin S: Interprofessional collaboration in the hospital: strategies and meanings. Journal of Health Services \& Research Policy 2004; 9:218-225

152. Haig KM, Sutton S, Whittington J: SBAR: a shared mental model for improving communication between clinicians. Jt Comm J Qual Patient Saf 2006; 32:167-175

153. Joint Commission Resources: The SBAR Technique: Improves Communication, Enhances Patient Safety. Joint Commission Perspectives on Patient Safety 2005; 5:1-8

154. Featherstone P, Chalmers T, Smith GB: RSVP: a system for communication of deterioration in hospital patients. Br J Nurs 2008; 17:860-864

155. Andrews T, Waterman H: Packaging: a grounded theory of how to report physiological deterioration effectively. $J$ Adv Nurs 2005; 52:473-481 
156. DeVita M, Smith G, Adam S, et al: Identifying the hospitalised patient in crisis: a consensus conference on the afferent limb of rapid response systems. Resuscitation 2010; 81:375-382

157. Sebat F, editor. Designing, implementing, and enhancing a rapid response system. Chicago: Society of Critical Care Medicine; 2009

158. Rivers E, Nguyen B, Havstad S, et al: Early goal-directed therapy in the treatment of severe sepsis and septic shock. N Engl J Med 2001; 345:1368-1377

159. Surviving Sepsis Campaign. 2007 [28 December 2009]; Available from: http://www.survivesepsis.org/content.php?name=surviving.php

160. Baldwin LN, Smith SA, Fender V, et al: An audit of compliance with the sepsis resuscitation care bundle in patients admitted to A\&E with severe sepsis or septic shock. Int Emerg Nurs 2008; 16:250-256

161. Gao F, Melody T, Daniels D, et al: The impact of compliance with 6-hour and 24-hour sepsis bundles on hospital mortality in patients with severe sepsis: a prospective observational study. Critical Care 2005; 9:R764 - R770

162. McNeill G, Dixon M, Jenkins P: Can acute medicine units in the UK comply with the Surviving Sepsis Campaign's six-hour care bundle? Clin Med 2008; 8:163-165

163. Carlbom DJ, Rubenfeld GD: Barriers to implementing protocol-based sepsis resuscitation in the emergency department--results of a national survey. Crit Care Med 2007; 35:2525-2532

164. Nguyen HB, Lynch EL, Mou JA, et al: The utility of a quality improvement bundle in bridging the gap between research and standard care in the management of severe sepsis and septic shock in the emergency department. Acad Emerg Med 2007; 14:1079-1086

165. Trzeciak S, Dellinger RP, Abate NL, et al: Translating research to clinical practice: a 1year experience with implementing early goal-directed therapy for septic shock in the emergency department. Chest 2006; 129:225-232

166. Mikkelsen M, Miltiades A, Gaieski D, et al: Serum lactate is associated with mortality in severe sepsis independent of organ failure and shock. Crit Care Med 2009; 37:16701677

167. Amaravadi R, Dimick J, Pronovost P, et al: ICU nurse-to-patient ratio is associated with complications and resource use after esophagectomy. Intensive Care Med 2000; 26:1857-1862

168. Dimick J, Swoboda S, Pronovost P, et al: Effect of nurse-to-patient ratio in the intensive care unit on pulmonary complications and resource use after hepatectomy. Am J Crit Care 2001; 10:376-382

169. Kovner C, Gergen P: Nurse staffing levels and adverse events following surgery in U.S. hospitals. Image J Nurs Sch 1998; 30:315-321

170. Pronovost PJ, Jenckes, M.W., Dorman, T., Garrett, E., Breslow, M.J., Rosenfeld, B.A., et al. : Organizational characteristics of intensive care units related to outcomes of abdominal aortic surgery. JAMA 1999; 281:1310-1317

171. Unruh L: The effect of LPN reductions on RN patient load. J Nurs Adm 2003; 33:201208

172. Giraud T, Dhainaut J, al e: Iatrogenic complications in adult intensive care units: a prospective two-center study. Crit Care Med 1993; 21:40-51

173. Aiken LH, Clarke SP, Sloane DM, et al: Hospital nurse staffing and patient mortality, nurse burnout, and job dissatisfaction. JAMA 2002; 288:1987-1993

174. Clarke S, Donaldson N. Nurse staffing and patient care quality and safety. Patient Safety and Quality - An Evidence-Based Handbook for Nurses: AHRQ; 2008

175. Needleman J, Buerhaus P, Mattke S, et al: Nurse-staffing levels and the quality of care in hospitals. N Engl J Med 2002; 346:1715-1722 
176. Fridkin $S$, Pear $S$, al e: The role of understaffing in central venous catheter-associated bloodstream infections. Infect Control Hosp Epidemiol 1996; 17:150-158

177. Picard KM, O'Donoghue SC, Young-Kershaw DA, et al: Development and implementation of a multidisciplinary sepsis protocol. Crit Care Nurse 2006; 26:43-54

178. Sivayoham N: Management of severe sepsis and septic shock in the emergency department: a survey of current practice in emergency departments in England. Emerg Med J 2007; 24:422

179. Surviving Sepsis Campaign. Implementing the Surviving Sepsis Campaign manual: Society of Critical Care Medicine; 2005. Available from: http://www.survivingsepsis.com/files/Implementing\%20the\%20Surviving $\% 20$ Sepsis $\% 2$ 0Campaign.pdf

180. British Thoracic Society, Emergency Oxygen Guideline Group: Emergency oxygen use in adult patients. Thorax 2008; 63, Suppl VI:

181. Resuscitation Council UK: Advanced Life Support. 5th ed. London: Resuscitation Council UK; 2006

182. Robson W, Webster S, Blakemore K, et al: The use of a patient group direction to ensure prompt treatment of postoperative hypotension in orthopaedic patients. Journal of Orthopaedic Nursing 2003; 7:197-200

183. McKendry M, McGloin H, Saberi D, et al: Randomised controlled trial assessing the impact of a nurse delivered, flow monitored protocol for optimisation of circulatory status after cardiac surgery. Br Med J 2004; 329:258

184. Phillips S: Legislative update. Twentieth anniversary. After 20 years, APNs are still standing together. Nurse Practitioner 2008; 33:10-34

185. UK Department of Health. Improving patients' access to medicines: A guide to implementing nurse and pharmacist independent prescribing within the NHS in England 2006. Available from:

http://www.dh.gov.uk/prod_consum_dh/groups/dh_digitalassets/@dh/@en/documents/ digitalasset/dh_4133747.pdf

186. Australian \& New Zealand Society of Blood Transfusion Inc., Royal College of Nursing Australia. Guidelines for the administration of blood components. 2004 [28 December 2009]; Available from: http://www.anzsbt.org.au/publications/index.cfm

187. Royal College of Nursing. Right blood, right patient, right time: RCN guidance for improving transfusion practice. London2005 [28 December 2009]; Available from: http://www.rcn.org.uk/_data/assets/pdf_file/0009/78615/002306.pdf

188. Minton J, Clayton J, Sandoe J, et al: Improving early management of bloodstream infection: a quality improvement project. Br Med J 2008; 336:440-443

189. Natsch S, Kullberg BJ, van der Meer JW, et al: Delay in administering the first dose of antibiotics in patients admitted to hospital with serious infections. Eur J Clin Microbiol Infect Dis 1998; 17:681-684

190. Surviving Sepsis Campaign. Improve time to broad-spectrum antibiotics. Society of Critical Care Medicine; 2008 [28 December 2009]; Available from: http://www.survivingsepsis.org/Bundles/Individual_Changes/Pages/improve_antibiotic time.aspx

191. Thompson DS, Oberteuffer R, Dorman T: Sepsis alert and diagnostic system: integrating clinical systems to enhance study coordinator efficiency. Comput Inform Nurs 2003; 21:22-26; quiz 27-28

192. Boardman S, Richmond C, Robson W, et al: Prehospital management of a patient with severe sepsis. Journal of Paramedic Practice 2009; 1:183-188

193. Hollenberg S, Ahrens T, Annana D, et al: Practice parameters for hemodynamic support of sepsis in adult patients. Crit Care Med 2004; 32:1928-1948 
194. Ahrens T: Hemodynamics in sepsis. AACN Adv Crit Care 2006; 17:435-445

195. Maxwell D, Carrigan L, Merritt C, et al: Comparison of continuous central venous oxygen saturation and standard central venous catheters in septic patients at a large, non-academic tertiary medical center. Crit Care Med 2009; 37:A216

196. Donati A, Romanelli M, Botticelli L, et al: Recombinant activated protein C treatment improves tissue perfusion and oxygenation in septic patients measured by near-infrared spectroscopy. Crit Care 2009; 13:S12

197. Leone M, Blidi S, Antonini F, et al: Oxygen tissue saturation is lower in nonsurvivors than in survivors after early resuscitation of septic shock. Anesthesiology 2009; 111:366-371

198. Doerschug K, Delsing A, Schmidt G, et al: Impairments in microvascular reactivity are related to organ failure in human sepsis. Am J Physiol Heart Circ Physiol 2007; 293:H1065-H1071

199. Cohn SM, Nathens AB, Moore FA, et al: Tissue oxygenation saturation predicts the development of organ dysfunction during traumatic shock resuscitation. J Trauma 2007; 62:44-55

200. Bakker J, Jansen T: Don't take vitals, take a lactate. Intensive Care Med 2007; 33:18631865

201. Howell M, Donnino M, Clardy P, et al: Occult hypoperfusion and mortality in patients with suspected infection. Intensive Care Med 2007; 33:1892-1899

202. Micek S, Roubinian N, Heuring T, et al: Before-after study of a standardized hospital order set for the management of septic shock. Crit Care Med 2006; 34:2707-2713

203. Shorr A, Micek S, Jackson W, et al: Economic implications of an evidence-based sepsis protocol: can we improve outcomes and lower costs? Crit Care Med 2007; 35:12571262

204. Packman M, Rackow E: Optimum left heart filling pressure during fluid resuscitation of patients with hypovolemic and septic shock. Crit Care Med 1983; 11:165-169

205. Marik P, Baram M, Vahid B: Does central venous pressure predict fluid responsiveness? A systematic review of the literature and the tale of seven mares. Chest 2008; 134:172-178

206. Chytra I, Pradl R, Bosman R, et al: Esophageal Doppler-guided fluid management decreases blood lactate levels in multiple-trauma patients: a randomized controlled trial. Crit Care 2007; 22:1-9

207. Conway D, Mayall R, Abdul-Latif M, et al: Randomized controlled trial investigating the influence of intravenous fluid titration using esophageal Doppler monitoring during bowel surgery. Anesthesia 2002; 57:845-849

208. Gan T, Soppitt A, Maroof M, et al: Goal-directed intra-operative fluid administration reduces length of hospital stay after major surgery. Anesthesiology 2002; 97:820-826

209. Mythen M, Webb A: Peri-operative plasma volume expansion reduces the incidence of gut mucosal hypoperfusion during cardiac surgery. Arch Surg 1995; 130:423-429

210. National Health Service. Doppler guided intraoperative fluid management. NHS technology adoption center website 2010. Available from: http://www.technologyadoptioncentre.nhs.uk/assets/_files/documents/feb_10/nhs_ 126 6494444_NTAC_Doppler_Results_Feb_2010_.pdf

211. Sinclair S, James S, Singer M: Intraoperative intravascular volume optimization and length of hospital stay after repair of proximal femoral fracture: randomized controlled trial. Br Med J 1997; 315:909-912

212. Venn R, Steele A, Richardson P, et al: Randomized controlled trial to investigate influence of the fluid challenge on duration of hospital stay and perioperative morbidity in patients with hip fractures. Br J Anaesth 2002; 88:65-71 
213. Wakeling H, McFall M, Jenkins C, et al: Intraoperative esophageal Doppler guided fluid management shortens postoperative hospital stay after major bowel surgery. $\mathrm{Br} \mathrm{J}$ Anaesth 2005; 95:634-642

214. Eachempati S, et al: The clinical use of an esophageal Doppler monitor for hemodynamic monitoring in sepsis. Journal of Clinical Monitoring \& Computing 1999; $15: 223-225$

215. Marx G, et al: Assessing fluid responsiveness by stroke volume variation in mechanically ventilated patients with severe sepsis. Eur J Anaesthesiol 2004; 21:132138

216. Santolucito J: The role of peripherally inserted central catheters in the treatment of the critically-ill. Journal of the Association for Vascular Access 2007; 12:208-217

217. Heyland D, Dhaliwal R, Drover J, et al: Canadian clinical practice guidelines for nutrition support in mechanically ventilated, critically ill adult patients. $J$ Parenter Enteral Nutr 2003; 27:355-373

218. Giner M, Laviano A, Meguid MM, et al: In 1995 a correlation between malnutrition and poor outcome in critically ill patients still exists. Nutrition 1996; 12:23-29

219. Martindale R, McClave S, Vanek V, et al: Guidelines for the provision and assessment of nutrition support therapy in the adult critically ill patient: Society of Critical Care Medicine and American Society for Parenteral and Enteral Nutrition: Executive Summary. Crit Care Med 2009; 37:1757-1761

220. American Dietetic Association. Critical illness evidence-based nutrition practice guideline2006: Available from: http://www.guideline.gov/summary/summary.aspx?doc_id=12818

221. Doig G. Evidence-based guidelines for nutritional support of the critically ill: results of a bi-national guideline development conference. In: (ANZICS) AaNZICS, editor.: Australian and New Zealand Intensive Care Society (ANZICS); 2005

222. Kreymann K, Berger M, Deutz N, et al: ESPEN Guidelines on Enteral Nutrition: Intensive care. Clinical Nutrition 2006; 25:210-223

223. Jones NE, Dhaliwal R, Day AG, et al: Factors predicting adherence to the Canadian Clinical Practice Guidelines for nutrition support in mechanically ventilated, critically ill adult patients. Journal of Critical Care 2008; 23:301-307

224. Gramlich L, Kichian K, Pinilla J, et al: Does enteral nutrition compared to parenteral nutrition result in better outcomes in critically ill adult patients? A systematic review of the literature. Nutrition 2004; 20:843-848

225. Simpson F, Doig GS: Parenteral vs. enteral nutrition in the critically ill patient: a metaanalysis of trials using the intention to treat principle. Intensive Care Med 2005; 31:1223

226. Marik PE, Zaloga GP: Early enteral nutrition in acutely ill patients: a systematic review. Crit Care Med 2001; 29:2264-2270

227. Koroloff N, Boots R, Lipman J, et al: A randomised controlled study of the efficacy of hypromellose and Lacri-Lube combination versus polyethylene/Cling wrap to prevent corneal epithelial breakdown in the semiconscious intensive care patient. Intensive Care Med 2004; 30:1122-1126

228. Hernandez E, Mannis M: Superficial keratopathy in intensive care unit patients. Am J Ophthalmol 1997; 124:212-216

229. Imanaka H, Taenaka N, Nakamura J, et al: Ocular surface disorders in the critically ill. Anesth Analg 1997; 85:343-346

230. Lenart SB, Garrity JA: Eye care for patients receiving neuromuscular blocking agents or propofol during mechanical ventilation. Am J Crit Care 2000; 9:188-191 
231. Marshall A, Elliott R, Rolls K, et al: Eyecare in the critically ill: Clinical practice guideline. Aust Crit Care 2008; 2:97-109

232. Bates J, Dwyer R, O'Toole L, et al: Corneal protection in critically ill patients: a randomized controlled trial of three methods. Clinical Intensive Care 2004; 15:23-26

233. European Pressure Ulcer Advisory Panel (EPUAP), National Pressure Ulcer Advisory Panel (NPUAP). Pressure ulcer prevention: Quick reference guide2009a: Available from: http://www.epuap.org/guidelines.html

234. European Pressure Ulcer Advisory Panel (EPUAP), National Pressure Ulcer Advisory Panel (NPUAP). Pressure ulcer treatment: Quick reference guide2009b: Available from: http://www.epuap.org/guidelines.html

235. Elliott R, McKinley S, Fox V: Quality improvement program to reduce the prevalence of pressure ulcers in an intensive care unit. Am J Crit Care 2008; 17:328-334

236. de Laat EHEW, Schoonhoven L, Pickkers P, et al: Epidemiology, risk and prevention of pressure ulcers in critically ill patients: a literature review. J Wound Care 2006; 15:269 $-275$

237. Boyle M, Green M: Pressure sores in intensive care: defining their incidence and associated factors and assessing the utility of two pressure sore risk assessment tools. Aust Crit Care 2001; 14:24-30

238. Fife C, Otto G, Capsuto EG, et al: Incidence of pressure ulcers in a neurologic intensive care unit. Crit Care Med 2001; 29:283-290

239. Seongsook J, Ihnsook J, Younghee L: Validity of pressure ulcer risk assessment scales; Cubbin and Jackson, Braden, and Douglas scale. Int J Nurs Stud 2004; 41:199-204

240. Kottner J, Raeder K, Halfens R, et al: A systematic review of interrater reliability of pressure ulcer classification systems. J Clin Nurs 2009; 18:315-336

241. Stausberg J, Kiefer E: Classification of pressure ulcers: a systematic literature review. Stud Health Technol Inform 2009; 146:511-515

242. Hopkins R, Spuhler V, Thomsen G: Transforming ICU culture to facilitate early mobility. Crit Care Clin 2007; 23:81-96

243. Watson R, Carcillo J: Scope and epidemiology of pediatric sepsis. Pediatr Crit Care Med 2005; 6:S3-5

244. Watson R, Carcillo J, Linde-Zwirble W, et al: The epidemiology of severe sepsis in children in the United States. Am J Respir Crit Care Med 2003; 167:695-701

245. von Rosenstiel N, von Rosenstiel I, Adam D: Management of sepsis and septic shock in infants and children. Paediatr Drugs 2001; 3:9-27

246. Goldstein B, Giroir B, Randolph A: International pediatric sepsis consensus conference: definitions for sepsis and organ dysfunction in pediatrics. Pediatr Crit Care Med 2005; $6: 2-8$

247. Brierley J, Carcillo J, Choong K, et al: Clinical practice parameters for hemodynamic support of pediatric and neonatal septic shock: 2007 update from the American College of Critical Care Medicine. Crit Care Med 2009; 37:666-688

248. Parker M, Hazelzet J, Carcillo J: Pediatric considerations. Crit Care Med 2004; 32:S591-594

249. Aneja R, Carcillo J: What is the rationale for hydrocortisone treatment in children with infection-related adrenal insufficiency and septic shock? Arch Dis Child 2007; 92:165169

250. Dichter C, Curley M. Shock. In: Curley M, Moloney-Harmon P, editors. Critical Care Nursing of Infants and Children. 2nd ed. Philadelphia, PA: WB Saunders; 2001. pp 937

251. Hebbar K, Rigby M, Felner E, et al: Neuroendocrine dysfunction in pediatric critical illness. Pediatr Crit Care Med 2009; 10:35-40 
252. Sorce L: Adverse responses: sedation, analgesia and neuromuscular blocking agents in critically ill children. Crit Care Nurs Clin North Am 2005; 17:441-450, xi-xii

253. Moloney-Harmon P: Pediatric sepsis: the infection unto death. Crit Care Nurs Clin North Am 2005; 17:417-429, xi

254. Curley M, Harris S, Fraser K, et al: State Behavioral Scale: a sedation assessment instrument for infants and young children supported on mechanical ventilation. Pediatr Crit Care Med 2006; 7:107-114

255. Barton P, Kalil A, Nadel S, et al: Safety, pharmacokinetics, and pharmacodynamics of drotrecogin alfa (activated) in children with severe sepsis. Pediatrics 2004; 113:7-17 
Table 1. Definition of Sepsis $(4,137)$

\begin{tabular}{|c|c|}
\hline Term & Definition \\
\hline $\begin{array}{l}\text { Sepsis (also } \\
\text { referred to as } \\
\text { Systemic } \\
\text { Inflammation in } \\
\text { Response to } \\
\text { Infection) }\end{array}$ & 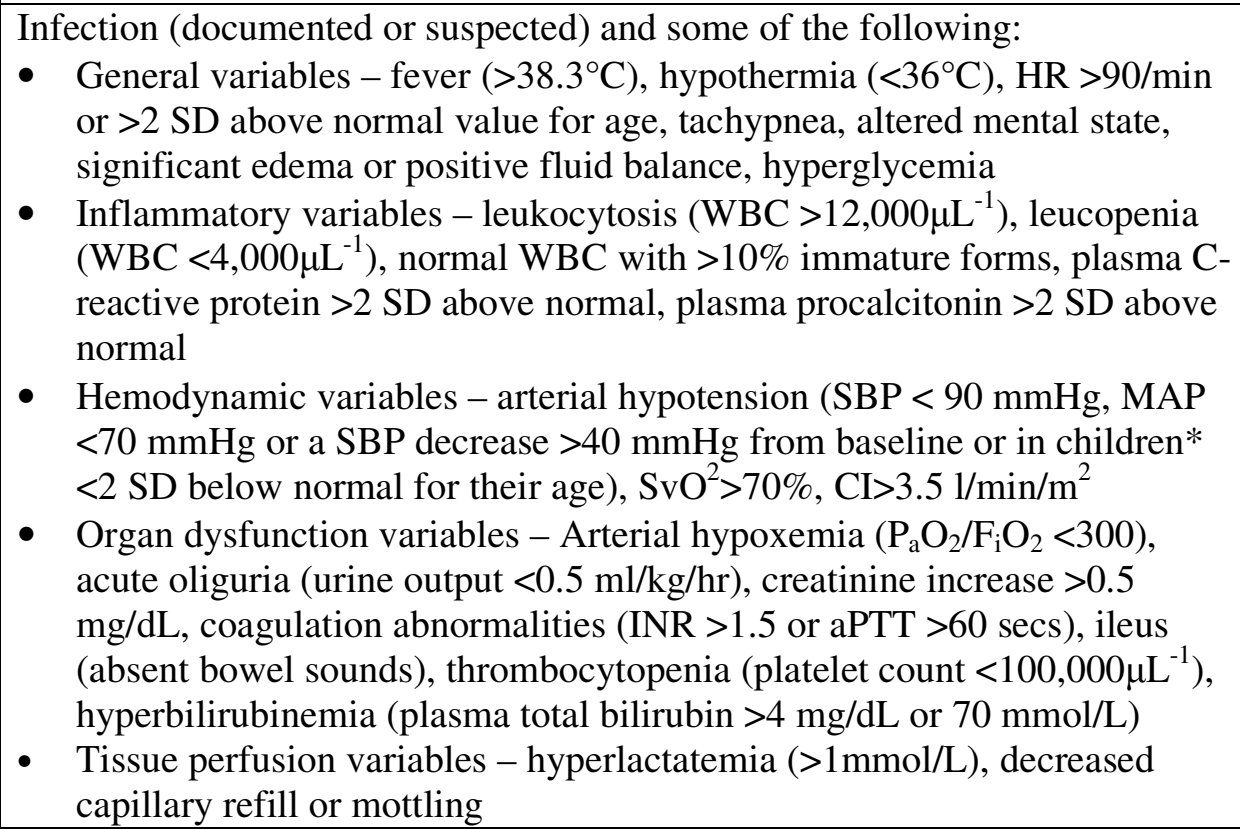 \\
\hline Severe sepsis & Sepsis complicated by organ dysfunction \\
\hline Septic shock & $\begin{array}{l}\text { Acute circulatory failure characterized by persistent arterial hypotension } \\
\text { despite adequate volume resuscitation and unexplained by other causes. } \\
\text { Hypotension is defined as: } \\
\text { - SBP }<90 \mathrm{mmHg} \text { or in children* }<2 \mathrm{SD} \text { below normal for their age } \\
\text { - MAP }<60 \mathrm{mmHg} \text {, or } \\
\text { - reduction in } \mathrm{SBP}>40 \mathrm{mmHg} \text { from baseline }\end{array}$ \\
\hline
\end{tabular}

* see pediatric considerations section for further clarification of diagnosis in children

SD - standard deviations

WBC - while blood cells

SBP - systolic blood pressure

MAP - mean arterial pressure

$\mathrm{SvO} 2$ - saturation of oxygen in venous blood

$\mathrm{CI}$ - cardiac index 
Table 2 GRADE criteria $(4,5)$

\begin{tabular}{|c|c|}
\hline Strength of Evidence & Quality of Evidence \\
\hline $1-$ Strong & A - high, e.g. well conducted RCT \\
\hline \multirow[t]{3}{*}{$2-$ Weak } & $\begin{array}{l}\text { B - Moderate, e.g. downgraded RCT or upgraded observational } \\
\text { studies }\end{array}$ \\
\hline & C - Low, e.g. well done observational studies \\
\hline & D - Very low, e.g. case series or expert opinion \\
\hline \multicolumn{2}{|c|}{ Factors influencing strength of evidence } \\
\hline \multicolumn{2}{|c|}{$\begin{array}{l}\text { Methodological quality - poor planning and implementation increasing likelihood of bias is likely } \\
\text { to decrease rating }\end{array}$} \\
\hline \multicolumn{2}{|c|}{ Importance of outcome - highly desirable outcomes are likely to increase rating } \\
\hline \multicolumn{2}{|c|}{ Magnitude of treatment effect $-\mathrm{RR}>2$ with no plausible confounders is likely to increase rating } \\
\hline \multicolumn{2}{|c|}{ Precision of estimate of treatment effect - highly precise results are likely to increase rating } \\
\hline \multicolumn{2}{|c|}{ Inconsistency of results - multiple studies with inconsistent results is likely to decrease rating } \\
\hline \multicolumn{2}{|c|}{ Directness of evidence - indirect evidence (e.g. different populations) is likely to decrease rating } \\
\hline \multicolumn{2}{|c|}{$\begin{array}{l}\text { Risks associated with therapy - significant known risks or burden of therapy are likely to } \\
\text { decrease rating }\end{array}$} \\
\hline \multicolumn{2}{|c|}{ Costs - significant costs associated with therapy are likely to decrease rating } \\
\hline
\end{tabular}




\section{Table 3. Clinical Signs of Sepsis}

Systemic Inflammatory Response Syndrome: two or more of the following conditions can indicate sepsis:

Temperature $>38^{\circ} \mathrm{C}$ or $<36^{\circ} \mathrm{C}$

Heart rate $>90$ beats/min

Respiratory rate $>20$ breaths $/ \mathrm{min}$ or $\mathrm{PaCO}_{2}<32 \mathrm{~mm} \mathrm{Hg}(<4.3 \mathrm{kPa})$

WBC $>12,000$ cells $/ \mathrm{mm}^{3},<4,000$ cells $/ \mathrm{mm}^{3}$, or $>10 \%$ immature (band) forms

Additional signs and symptoms:

Chills

Hypotension

Decreased skin perfusion

Decreased urine output

Significant edema or positive fluid balance ( $>20 \mathrm{~mL} / \mathrm{kg}$ over 24 hours)

Decreased capillary refill or mottling

Hyperglycemia (plasma glucose $>120 \mathrm{mg} / \mathrm{dL}$ ) in the absence of diabetes

Unexplained change in mental status

Adapted from Levy et al. (137) 


\section{Table 4: The Sepsis Six Interventions}

- Give high flow oxygen

- Take blood cultures

- Give IV antibiotics

- Start IV fluid resuscitation

- Check hemoglobin and lactate

- Measure accurate hourly urine output

Adapted from Surviving Sepsis Campaign $(144,159)$ 


\section{Table 5: Strategies for Integrating the Surviving Sepsis Guidelines in Nursing Practice}

Strategies to promote the integration of the Surviving Sepsis Campaign Guidelines in clinical practice

1. Create a multidisciplinary team and map out a timeline for implementing the strategies.

2. Enlist the participation of nurse champions in leading the initiatives. Many of the recommendations involve aspects of nursing care, and nurses can play an important role in promoting implementation of the guidelines.

3. Integrate the use of the Surviving Sepsis Campaign Guidelines as a performance improvement initiative for the ICU and non critical care areas.

4. Target processes to ensure successful adoption of the guidelines.

5. Include discussion of the guidelines in venues such as daily rounds, grand rounds, and critical care conference. Consider the use of a daily goal sheet to ensure that the components of the Surviving Sepsis Campaign Guidelines, including the sepsis bundles, are addressed on a ongoing basis.

6. Promote early identification of sepsis. Early identification of sepsis can help to promote prompt treatment.

Adapted from Kleinpell, 2005 (138) 
Table 6. Pharmacologic Therapies Used in Septic Shock (250)

\begin{tabular}{|c|c|c|c|c|}
\hline Drug & Site of action & Dose $(\mu \mathrm{g} / \mathrm{kg} / \mathrm{min})$ & Primary Effect & Secondary Effect \\
\hline Dopamine & $\begin{array}{l}\text { Dopaminergic } \\
\text { Dopaminergic and } \beta_{1} \\
\alpha\end{array}$ & $\begin{array}{l}2-5 \\
2-10 \\
10-20\end{array}$ & $\begin{array}{l}\text { Increase renal perfusion } \\
\text { Inotropy } \\
\text { Chronotropy } \\
\text { Increase renal perfusion } \\
\text { Vasoconstriction }\end{array}$ & Dysrhythmia \\
\hline Norepinephrine & $\alpha>\beta$ & $2-10$ & $\begin{array}{l}\text { Vasoconstriction } \\
\text { Inotropy }\end{array}$ & $\begin{array}{l}>\mathrm{MVO}_{2} \\
\text { Dysrhythmias } \\
<\text { Renal blood flow }\end{array}$ \\
\hline Epinephrine & $\alpha$ and $\beta$ & $0.05-1.5$ & $\begin{array}{l}\text { Vasoconstriction } \\
\text { Inotropy } \\
\text { Chronotropy }\end{array}$ & $\begin{array}{l}>\mathrm{MVO}_{2} \\
\text { Dysrhythmias } \\
<\text { Renal blood flow }\end{array}$ \\
\hline Dobutamine & $\beta_{1}$ & $5-20$ & Inotropy & $\begin{array}{l}\text { Tachycardia } \\
\text { Dysrhythmia } \\
\text { Vasodilatation } \\
\text { Hypotension }\end{array}$ \\
\hline $\begin{array}{l}\text { Sodium } \\
\text { nitroprusside }\end{array}$ & NA & 0.5-10 (light sensitive) & Vasodilatation (balanced) & $\begin{array}{l}<\mathrm{PVR} \\
>\mathrm{V} / \mathrm{Q} \text { mismatch } \\
\text { Cyanide toxicity }\end{array}$ \\
\hline Nitroglycerin & NA & $0.2-20$ & Vasodilatation (venous) & $\begin{array}{l}<\mathrm{PVR} \\
>\mathrm{ICP}\end{array}$ \\
\hline Amrinone & NA & $\begin{array}{l}5-10 \text { (load with up to } 3 \\
\mathrm{mg} / \mathrm{kg} \text { over } 20 \mathrm{~min})\end{array}$ & $\begin{array}{l}\text { Inotropy } \\
\text { Vasodilatation }\end{array}$ & $\begin{array}{l}\text { Dysrhythmias } \\
<\text { PVR } \\
\text { Thrombocytopenia }\end{array}$ \\
\hline Milrinone & NA & $\begin{array}{l}0.75-1.0 \text { (load with } 75 \\
\mu \mathrm{g} / \mathrm{kg} \text { over } 20 \mathrm{~min}\end{array}$ & & \\
\hline
\end{tabular}

* Difficult to predict the dose-response effect. Management requires individual titration at the bedside.

$\mathrm{MVO}_{2}$, Myocardial oxygen consumption; PVR, pulmonary vascular resistance; V/Q, ventilation/perfusion; ICP, intracranial pressure. 